\title{
Profiling the tyrosine phosphoproteome of different mouse mammary tumour models reveals distinct, model-specific signalling networks and conserved oncogenic pathways
}

Naveid A Ali ${ }^{1 \dagger}$, Jianmin Wu ${ }^{1 \dagger}$, Falko Hochgräfe ${ }^{1,2 \dagger}$, Howard Chan ${ }^{1,3}$, Radhika Nair ${ }^{1}$, Sunny Ye ${ }^{1}$, Luxi Zhang ${ }^{1,3}$, Ruth J Lyons ${ }^{1}$, Mark Pinese ${ }^{1}$, Hong Ching Lee ${ }^{1}$, Nicola Armstrong ${ }^{4}$, Christopher J Ormandy ${ }^{1}$, Susan J Clark', Alexander Swarbrick ${ }^{1}$ and Roger J Daly ${ }^{1,3^{*}}$

\begin{abstract}
Introduction: Although aberrant tyrosine kinase signalling characterises particular breast cancer subtypes, a global analysis of tyrosine phosphorylation in mouse models of breast cancer has not been undertaken to date. This may identify conserved oncogenic pathways and potential therapeutic targets.

Methods: We applied an immunoaffinity/mass spectrometry workflow to three mouse models: murine stem cell virus-Neu, expressing truncated Neu, the rat orthologue of human epidermal growth factor receptor 2, Her2 (HER2); mouse mammary tumour virus-polyoma virus middle T antigen (PyMT); and the $p 53^{-1-}$ transplant model (p53). Pathways and protein-protein interaction networks were identified by bioinformatics analysis. Molecular mechanisms underpinning differences in tyrosine phosphorylation were characterised by Western blot analysis and array comparative genomic hybridisation. The functional role of mesenchymal-epithelial transition factor (Met) in a subset of p53-null tumours was interrogated using a selective tyrosine kinase inhibitor (TKI), small interfering RNA (siRNA)-mediated knockdown and cell proliferation assays.

Results: The three models could be distinguished on the basis of tyrosine phosphorylation signatures and signalling networks. HER2 tumours exhibited a protein-protein interaction network centred on avian erythroblastic leukaemia viral oncogene homologue 2 (Erbb2), epidermal growth factor receptor and platelet-derived growth factor receptor a, and they displayed enhanced tyrosine phosphorylation of ERBB receptor feedback inhibitor 1. In contrast, the PyMT network displayed significant enrichment for components of the phosphatidylinositol 3-kinase signalling pathway, whereas p53 tumours exhibited increased tyrosine phosphorylation of Met and components or regulators of the cytoskeleton and shared signalling network characteristics with basal and claudin-low breast cancer cells. A subset of p53 tumours displayed markedly elevated cellular tyrosine phosphorylation and Met expression, as well as Met gene amplification. Treatment of cultured p53-null cells exhibiting Met amplification with a selective Met TKI abrogated aberrant tyrosine phosphorylation and blocked cell proliferation. The effects on proliferation were recapitulated when Met was knocked down using siRNA. Additional subtypes of p53 tumours exhibited increased tyrosine phosphorylation of other oncogenes, including Peak1/SgK269 and Prex2.

(Continued on next page)
\end{abstract}

\footnotetext{
* Correspondence: roger.daly@monash.edu

†Equal contributors

${ }^{1}$ Cancer Research Program, The Kinghorn Cancer Centre, Garvan Institute of Medical Research, 370 Victoria Street, Sydney, NSW 2010, Australia

${ }^{3}$ Current Address: Department of Biochemistry and Molecular Biology, School of Biomedical Sciences, Monash University, Level 1, Building 77, Clayton, VIC 3800, Australia

Full list of author information is available at the end of the article
} 
(Continued from previous page)

Conclusion: This study provides network-level insights into signalling in the breast cancer models utilised and demonstrates that comparative phosphoproteomics can identify conserved oncogenic signalling pathways. The Met-amplified, p53-null tumours provide a new preclinical model for a subset of triple-negative breast cancers.

\section{Introduction}

It is well established that tyrosine kinase signalling pathways play major roles in breast cancer development and progression. Evidence for this includes (1) the amplification of the receptor tyrosine kinase (RTK) human epidermal growth factor receptor 2 (HER2)/avian erythroblastic leukaemia viral oncogene homologue 2 (erbB2) in approximately $25 \%$ of breast cancers [1]; (2) the presence of activating mutations in PIK3CA, encoding the p110 $\alpha$ catalytic subunit of phosphatidylinositol 3-kinase (PI3K), in approximately $30 \%$ of cases [2]; and dysregulation of other signalling intermediates such as the non-RTK Src [3], the docking protein Gab2 [4] and the serine/threonine kinase Akt3 [5]. In addition, an array of data from cell line and mouse models of breast cancer confirm the oncogenic or tumour suppressor roles of particular tyrosine-phosphorylated signalling proteins [6-9]. These findings have led to the development of small-molecule- and antibodybased targeted therapies that have either entered the clinic or are currently undergoing clinical trials, including the use of trastuzumab to treat HER2-positive breast cancer [10].

Gene expression profiling has revealed that breast cancer can be subclassified into luminal A, luminal B, HER2, basal and claudin-low subtypes, which differ in terms of patient prognosis and response to therapy [11]. Basal and claudin-low breast cancers present a major clinical challenge, as their frequent triple-negative phenotype (lacking HER2, oestrogen and progesterone receptors) confers intrinsic resistance to HER2-targeted and endocrine therapy [12]. The HER2 subtype is characterised by amplification of the corresponding gene, and other breast cancer subtypes also exhibit characteristic perturbations in tyrosine kinase signalling. For example, increased expression of the RTKs Met and epidermal growth factor receptor (Egfr) are associated with basal and triple-negative breast cancers [13-15], and, at least in cell line models, the basal and claudin-low subtypes are characterised by a prominent Src family kinase (SFK)-governed network [16,17]. Further characterisation of the signalling networks associated with different breast cancer subtypes may identify novel therapeutic targets and new applications for existing therapies, as well as biomarkers that aid patient stratification for therapy.

Genetically engineered mouse (GEM) models have greatly contributed to our understanding of the mechanisms and functions of particular oncogenes and tumour suppressors implicated in breast cancer, as well as biological processes involved in tumour progression [18]. These include GEM models in which normal or activated forms of neu (the rat homologue of HER2/ erbB2) are expressed in the mammary gland [8], as well as the polyoma virus middle $\mathrm{T}$ antigen (PyMT) model [19]. PyMT mimics an activated RTK, localising to the plasma membrane, as well as in intracellular membranes, where it is phosphorylated on specific tyrosine residues by particular SFKs. Phosphorylation of PyMT creates binding sites for Shc (at Y250), the p85 subunit of PI3K (at Y315) and phospholipase $\mathrm{C} \gamma 1$ (PLC $\gamma 1$, at Y322), and key roles for the Y250 and Y315/Y322 sites in mammary tumourigenesis have been demonstrated [20]. Interestingly, transcript profiling has demonstrated that mouse mammary tumour virus (MMTV)-Neu and MMTV-PyMT model tumours are relatively homogeneous and exhibit gene expression similarities to human luminal-type cancers [21]. In contrast, the p53-null transplant model of mammary tumourigenesis is characterised by tumours exhibiting histological and molecular heterogeneity, as well as genetic instability [22,23]. Indeed, transcript profiling has demonstrated that p53-null tumours can be classified into basallike, luminal and claudin-low subtypes characterised by distinct genomic copy number changes [22].

An important concept emanating from research using GEM models is that comparative genomic and transcriptomic strategies, wherein particular mouse tumours are compared to human breast cancer subtypes, can be utilised identify conserved mechanisms essential for disease development and progression [21,22,24,25]. In this study, we undertook global tyrosine phosphorylation profiling of three GEM models of breast cancer: a HER2 model featuring expression of an activated form of the receptor lacking the extracellular domain [26], as well as the MMTV-PyMT and p53-null transplant models. This enabled characterisation of the tyrosine phosphorylation-based signalling networks characteristic of each tumour type, revealed similarities and differences between these tumour models, and identified oncogenic pathways conserved in the human disease.

\section{Methods \\ Plasmids}

Neu-pMIL was used to generate the HER2 breast cancer model. This expresses a truncated form of Neu 
(approximately 647 to 1,260 amino acids, the rodent orthologue of Her2) with elevated activity due to truncation of the extracellular domain [27]. Truncated Neu was subcloned from Neu-pLJ by digestion using Sal1 followed by subcloning into pENTR2B (Invitrogen, Mulgrave, Victoria, Australia). The gene was subsequently cloned into pMIL, a derivative of pMig [28] that expresses a luciferase marker, to generate Neu-pMIL, in which expression of Neu is driven by the murine stem cell virus (MSCV) promoter. The Gateway LR recombination reaction was used as per the manufacturer's instructions (Invitrogen).

\section{Generation of tumours}

\section{MSCV-Neu (HER2) tumours}

Primary mammary epithelial cells from $\mathrm{FVB} / \mathrm{N}$ mice were cultured and retrovirally transduced with truncated Neu encoded by Neu-pMIL as described previously $[26,29,30]$. Cells were transplanted into the cleared mammary fat pad of naïve $\mathrm{FVB} / \mathrm{N}$ recipients within 2 days of retroviral transduction.

\section{Tp53-null tumours}

Tp53-null (p53) mice from The Jackson Laboratory (stock no. 002899; Bar Harbor, ME, USA) were on an FVB/N background. Mammary epithelium from 8-weekold mice was transplanted to the cleared mammary fat pad of naïve BL/6 (clone 5101) or FVB/N (all other clones) recipients as described previously [16,31].

Mice were aged for up to 12 months to permit spontaneous tumour formation [26]. Tumour fragments were passaged into the cleared mammary fat pad of naïve mice as previously described [26] (Additional file 1: Figure S1).

\section{PyMT-transformed tumours}

PyMT tumours were derived from MMTV-PyMT-transgenic mice on an FVB/N background as previously described [32]. All animal work was approved by the animal ethics committee of Garvan Institute of Medical Research, St Vincent's Hospital.

\section{Phosphotyrosine peptide enrichment}

Resected mouse mammary tumours were lysed in $8 \mathrm{M}$ urea, $20 \mathrm{mM}$ 2-[4-(2-hydroxyethyl)piperazin-1-yl]ethanesulfonic acid (HEPES), $2.5 \mathrm{mM}$ sodium pyrophosphate, $1 \mathrm{mM} \beta$-glycerol phosphate, $1 \mathrm{mM}$ sodium orthovanadate, $1 \mathrm{mM}$ ethylenediaminetetraacetic acid and $1 \mathrm{mM}$ Tris(2-carboxyethyl)phosphine, $\mathrm{pH}$ 8.0. Lysates were cleared by sonication and centrifugation prior to protease digestion, phosphotyrosine (pY) immunoprecipitation (IP) and nano-liquid chromatography tandem mass spectrometry (nano-LC-MS/MS). Lysates were quantitated, and $20 \mathrm{mg}$ of each sample were diluted to a final concentration of $1 \mathrm{M}$ urea with $20 \mathrm{mM}$ HEPES and digested overnight with trypsin at room temperature. Heavy proline (+6 Da)- and alanine (+4 Da)-labelled synthetic standard pY peptides of MK14, elongation factor Tu and EGFR were spiked into each sample at 5 pmol, $500 \mathrm{fmol}$ and $10 \mathrm{pmol}$, respectively, to enable normalisation of label-free quantitative values. Peptides were then desalted and concentrated using $\mathrm{C}_{18}$ Sep-Pak columns (Waters, Milford, MA, USA), and lyophilised. pY peptides were subject to IP using the PhosphoScan procedure (Cell Signaling Technology, Beverly, MA, USA) with pY100 antibodies as previously described [16]. pY-enriched peptides were dried using a vacuum centrifuge and stored at $-80^{\circ} \mathrm{C}$ prior to nanoLC-MS/MS analysis. All samples were analysed by nanoLC-MS/MS using two technical replicates.

Nano-liquid chromatography tandem mass spectrometry pY peptides were resuspended in $15 \mu$ l of MS buffer containing $1 \%$ formic acid, $2 \%$ acetonitrile (ACN) and $0.05 \%$ heptafluorobutyric acid and subjected to nanoLC-MS/MS. Peptides were separated by nano-LC using an UltiMate 3000 high-performance liquid chromatography and autosampler system (Dionex, Sunnyvale, CA, USA). Samples were concentrated and desalted onto a $\mathrm{C}_{18}$ microprecolumn (500 $\mu \mathrm{m} \times 2 \mathrm{~mm}$; Michrom Bioresources, Auburn, CA, USA) with $\mathrm{H}_{2} \mathrm{O}: \mathrm{ACN}$ (98:2, 0.05\% trifluoroacetic acid) at $15 \mu \mathrm{l} / \mathrm{min}$ for 4 minutes. The micro-precolumn was then switched online with a nano- $\mathrm{C}_{18}$ column (75 $\mu \mathrm{m} \times$ about $10 \mathrm{~cm}, 5 \mu \mathrm{m}, 200 \AA$ Magic; Michrom) and the reverse phase nano-eluent was subjected to positive nanoflow electrospray analysis in information-dependent acquisition (IDA) mode ( $250 \mathrm{nl} / \mathrm{min}$ for 30 minutes). Mass spectra were acquired on an Orbitrap Velos mass spectrometer (Thermo Electron, Waltham, MA, USA). In IDA mode, survey scans in the mass-to-charge ratio $(\mathrm{m} / \mathrm{z})$ range 350 to 1,750 were acquired with lock mass enabled. Up to the 15 most abundant ions ( $>5,000$ counts) with charge states greater than +2 were sequentially isolated and further subjected to MS/MS fragmentation within the linear ion trap using collisionally induced dissociation. MS/MS spectra were accumulated with an activation time of 30 milliseconds at a target value of 30,000 ions and a resolution of $60,000 . \mathrm{m} / \mathrm{z}$ ratios selected for MS/MS were dynamically excluded for 30 seconds.

\section{Protein identification}

The nano-LC-MS/MS .raw files were processed with MaxQuant software (version 1.1.1.25), which uses the Andromeda algorithm for data processing, database searching and protein identification [33]. Extracted peak lists were searched against the UniProtKB/Swiss-Prot Mus musculus database (Version 2010_10) containing 35,052 entries (including common contaminants) and a proportionally sized decoy database for false discovery rate (FDR) generation. The following search parameters were selected: 
fixed cysteine carbamidomethylation modification, variable methionine oxidation modification, variable protein $\mathrm{N}$-acetylation, and variable phosphorylation of serine, threonine and tyrosine. A minimum peptide length of six amino acids and up to two missed cleavages were allowed. The initial first search mass tolerance was $20 \mathrm{ppm}$ for precursor ions and 0.5 Da for fragment ions. Matches between runs were enabled with default settings and label-free quantitation enabled. The FDR was limited to $1 \%$ for both protein and peptide identification. For identification of the standard peptides, additional variable modifications of heavy proline $(+6 \mathrm{Da})$ and alanine $(+4 \mathrm{Da})$ were enabled.

\section{Phosphotyrosine peptide quantitation}

Raw pY peptide spectral intensities were extracted from the 'Evidence' output files generated in MaxQuant. These intensities were then normalised against pY peptide intensities for the heavy-labelled spiked-in peptide standards. These normalised intensities were then $\log _{10}$-transformed prior to all bioinformatics analyses, and their direct comparison enabled the relative quantitation of pY sites between the p53, PyMT and HER2 GEM models of breast cancer.

\section{Bioinformatics}

Raw MaxQuant output files were subjected to the following filtering criteria prior to their inclusion in further bioinformatics analysis: (1) contaminants and reversed matches were removed, ensuring that all identifications were reported with an FDR of $<1 \%$; and (2) pY sites were filtered for a minimum localisation probability confidence of 0.75 .

\section{Imputation}

The $k$-nearest neighbour [34] method was applied to impute missing values if a pY site was present in more than $50 \%$ of all samples; otherwise, the minimal value across all samples or the overall mean per sample for that pY site was used to replace missing values.

\section{Clustering and heat map generation}

Heat maps were generated using the $\mathrm{R}$ package gplots with hierarchical clustering applied to generate dendrograms for $\mathrm{pY}$ sites and samples. Euclidean distance with complete linkage was used, and the values were standardised at rows. The Bioconductor package limma was used to identify differences between the cancer models based on their pY-site expression levels. Empirical Bayes moderated $P$-values for contrasting and comparing expression between all samples were corrected for multiple testing by the Strimmer method as implemented in the $\mathrm{R}$ package fdrtool [35]. For all tests, $Q$-values less than 0.05 were considered significant. pY sites were thought of as class-specific (Her2-specific, p53-specific, PyMTspecific) on the basis of their contrast significance and the exhibition of increased spectral intensity for a particular sample.

\section{Random forest classifier}

The random forest classifier [36] was built using a twostep approach with the $\mathrm{R}$ package randomForest 2.15.0. In the first step, a classifier was built using all 381 consistently identified pY sites (that is, $\geq 75 \%$ of samples) as variables. In the second step, $17 \mathrm{pY}$ sites with the importance score $>1.2$ for each tumour model, which were calculated from the first classifier using a permutation-based approach, were used to build a new classifier. The out-of-bag estimate of error rates is $4.76 \%$ for both classifiers.

\section{Network analysis}

The protein-protein interaction data were extracted from Protein Interaction Network Analysis (PINA) [37,38]; substrate-kinase relationship information was obtained from PhosphoSitePlus [39]; and mouse-human orthologues extracted from MSOAR [40]. The networks were generated using a Cytoscape PINA4MS plugin (HC Lee, M Pinese, L Bourbon, I Rooman, RJ Daly, AV Biankin, J Wu, manuscript under preparation. URL: http://apps.cytoscape.org/ apps/pina4ms).

\section{Pathway analysis}

The KOBAS web server $[41,42]$ was applied for pathway enrichment analysis. The hypergeometric test was used to calculate the statistical significance of each pathway, followed by multiple test correction using the BenjaminiHochberg method [43].

\section{Antibodies and immunoblotting}

Antibodies against the following proteins were used, with immunoblotting carried out as previously described [44]: IRS1 (Upstate Biotechnology, Lake Placid, NY, USA); IRS1 pY612 (Invitrogen), Stat3, Crkl, Jak-1, P85 $\alpha$, CDK16, Cav1, ErbB3, phospho-ErbB3 (Tyr1328; Tyr1325 in mouse), ErbB2, Met, Met pY1234/1235 and pY (P-Tyr-100) (Cell Signaling Technology); phospho-p85 (Tyr467) (GeneTex, Irvine, CA, USA); platelet-derived growth factor receptor $\alpha($ PDGFR $\alpha$ ) and $\beta$-actin (Santa Cruz Biotechnology, Santa Cruz, CA, USA); ERBB receptor feedback inhibitor 1 (Errfi1) (Sigma-Aldrich, St Louis, MO, USA).

\section{DNA extraction}

Mouse tumour samples and liver tissue samples were harvested, snap-frozen and processed using the QIAamp DNA Mini Kit (QIAGEN, Valencia, CA, USA) according to the manufacturer's instructions. Briefly, up to $25 \mathrm{mg}$ of frozen tissue was ground and digested with proteinase $\mathrm{K}$ overnight at $56^{\circ} \mathrm{C}$. DNA was purified on a QIAamp spin column, eluted in $200 \mu \mathrm{l}$ of water and assessed for 
quality using a NanoDrop spectrophotometer (Thermo Scientific, Waltham, MA, USA). Samples were cleaned up by sodium acetate/ethanol precipitation to ensure $260 / 280$ and 260/230 absorbance ratios $>1.8$. DNA integrity was checked using gel electrophoresis.

\section{Array comparative genomic hybridisation}

Array comparative genomic hybridisation (aCGH) was performed by The Ramaciotti Centre for Gene Function Analysis (Randwick, NSW, Australia) on differentially labelled tumour DNA (Cy5) and sex-matched reference liver DNA (Cy3) using the Agilent SurePrint G3 mouse CGH $4 \times 180 \mathrm{~K}$ microarray platform (Agilent Technologies, Santa Clara, CA, USA). The aCGH data were analysed using circular binary segmentation [45] to translate intensity measurements into regions of equal copy numbers. The raw array data were median-normalised; duplicate probes were averaged; and the resulting data were smoothed to remove outliers prior to segmentation. The gain and loss status for each region was assigned by determining plateaus in an ordered plot of all segments by their mean $\log _{2}$ ratios. By this method, we denoted deletions to be segments with a mean value less than -0.5 , amplifications to have mean value between 0.5 and 1.5 and highly amplified regions to have a mean value greater than 1.5. Using this information, we merged segmental values across the genome to create a common set of copy number levels for each individual tumour. Analysis was carried out using the Bioconductor DNAcopy package [46] in R Project R2.15.2 software [47].

\section{Met inhibitor experiments}

Tumours were harvested and cellular preparations made using mechanical disruption and collagenase digestion as described previously [30]. Cells were cultured in vitro for two passages in mouse mammary epithelial cell media consisting of Dulbecco's modified Eagle's medium/Ham's F12 nutrient mixture supplemented with foetal calf serum, mouse epidermal growth factor, hydrocortisone, HEPES, insulin, gentamicin and penicillin/streptomycin [30], then trypsinised and seeded into 96-well plates at a density of 6,000 cells/well. The following day, cells were treated with the Met inhibitor PHA-665752 (Selleck Chemicals, Houston, TX, USA) at concentrations of $0.25 \mu \mathrm{M}, 0.5 \mu \mathrm{M}$ and $1 \mu \mathrm{M}$ or vehicle treated with $0.1 \%$ dimethyl sulphoxide (DMSO; Sigma-Aldrich). Cell proliferation was assessed and recorded using the IncuCyte ZOOM system (Essen BioScience, Ann Arbor, MI, USA). Briefly, cells were cultured for 5 days while images of cells inside each well (three images per well across four replicate wells) were captured every 2 hours. Proliferation was measured at each time point as a percentage of confluence, as determined using the IncuCyte software on the basis of automated analysis of captured images. Data are representative of two replicate experiments. For immunoblotting studies, cells at $70 \%$ to $90 \%$ confluence were treated with either vehicle control (DMSO) or Met TKI (1 $\mu \mathrm{M}$ final concentration) for 1 hour and then lysed in 1\% (vol/vol) Triton X-100 lysis buffer as previously described [48].

\section{Met knockdown and cell proliferation assay}

Met knockdown was performed using either individual (ON-TARGETplus Met siRNA 1 and 2) or SMARTpool siRNA targeting mouse Met (Dharmacon, Lafayette, CO, USA). The ON-TARGETplus nontargeting pool was used as a negative control. Briefly, cells were seeded into 96-well plates at a density of 4,500 cells/well 16 hours prior to transfection with $20 \mathrm{nM}$ of siRNA using Lipofectamine 2000 reagent (Invitrogen). Cell proliferation was assessed by MTS assay ([3-(4,5-dimethyl-2-yl)-5-(3-carboxymethoxyphenyl)-2-(4-sulfophenyl)-2H-tetrazolium, inner salt; Promega, Madison, WI, USA), according to the manufacturer's protocol, 72 hours posttransfection.

\section{Results}

\section{Tyrosine phosphorylation profiling of mouse mammary} tumour models

Because the mammary gland develops postnatally, murine mammary epithelium can be transferred into the surgically cleared fat pads of juvenile isogenic naïve recipients. The use of GEM as donors, or viral transduction of cells after extraction, allows the rapid generation of chimeric models in which implanted transgenic or gene-knockout mammary epithelium develops in an otherwise wild-type host $[21,26]$. Exploiting this strategy, we performed phosphoproteomic profiling using a combined immunoaffinity/LC-MS/MS approach across multiple MSCV-Neu (HER2), Tp53-null (p53) and PyMT tumours, as illustrated in Figure 1A. The lineage of each tumour from its original clone is outlined in Additional file 1: Figure S1A. In total, 856 unique pY sites were identified and quantitated from the tumour sample population with a FDR $<1 \%$. Following high-confidence localisation site filtering at $\geq 0.75$, 763 unique pY sites from 506 unique phosphoproteins remained, with approximately $63 \%$ being common across all tumour types (Figure 1B and Additional file 2: Table S1).

These pY sites mapped to 506 unique proteins. These proteins, which were grouped based on Gene Ontology functional categories, are illustrated in Additional file 3: Figure S2A. Additional file 3: Figure S2B shows an expanded section of the kinases identified in the three tumour types. The largest proportion of kinases comprised serine/ threonine kinases, followed by non-RTKs and RTKs. The least represented group comprised the dual-specificity kinases. The total pY site intensities were determined for the non-RTKs, which are shown in Additional file 3: Figure S2C. The most intense signal from the pY sites of non-RTKs was derived from SFKs (Yes, Fyn, Lyn and 


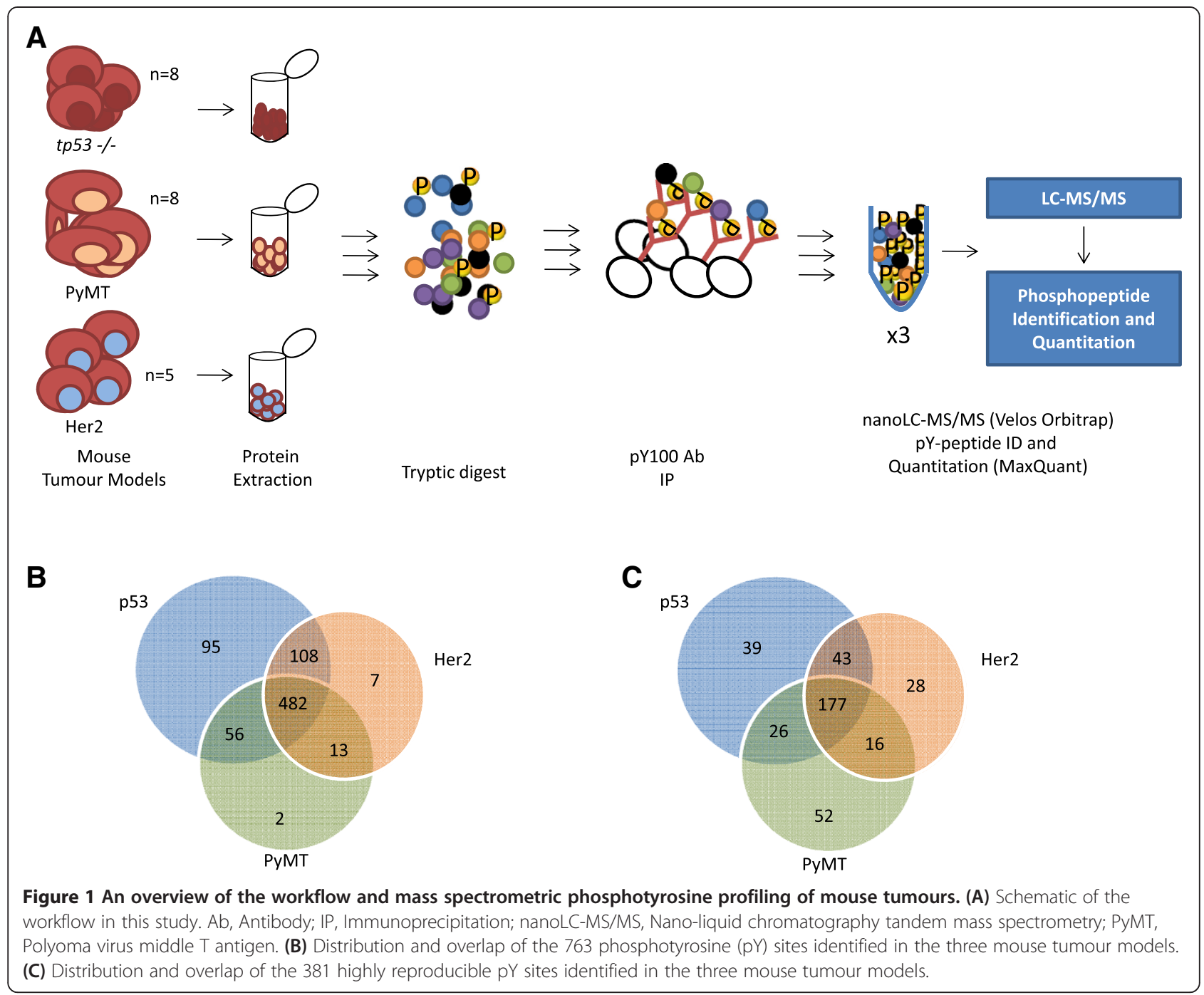

Hck), followed by focal adhesion kinase 1. When this approach was applied to RTKs, the most intense signal was derived from Met, followed by EphA2 (Additional file 3: Figure S2D).

To compare tyrosine phosphorylation patterns between the different tumour types and identify potential similarities, we undertook unsupervised hierarchical clustering. This revealed that two p53 tumour samples formed a distinct subgroup characterised by markedly elevated tyrosine phosphorylation of many pY sites (Additional file 4: Figure S3). The remaining tumour samples were distributed over a second major subgroup and exhibited a complex pattern of relationships. Of note, five PyMT tumours were closely related, and the majority of the p53 and HER2 tumours clustered together (Additional file 4: Figure S3). Also, although some tumours of shared origin, such as p53 tumours 1203 and 1204, clustered together, others, such as HER2 tumours HER 1197 and 3051, were well separated
(Additional file 1: Figure S1B), indicating that divergence can occur following serial transplantation.

To generate a list of pY sites characteristic of each tumour type, we first identified pY sites detected in at least $75 \%$ of the corresponding samples. Therefore, we selected pY sites that were identified in at least (1) six of eight p53 tumour samples, (2) six of eight PyMT tumour samples or (3) four of five Her2 tumour samples. Following this selection-filtering process, $381 \mathrm{pY}$ sites remained (Figure $1 \mathrm{C}$ and Additional file 5: Table S2). These sites mapped to 256 proteins, with 177 of them being found in all three tumour types. Upon unsupervised hierarchical clustering of this refined data set, all of the PyMT tumours were clustered together (Additional file 6: Figure S4). However, p53 tumours 1203 and 1204 still formed a distinct subgroup, and the HER2 tumours were divided into two groups, one related to PyMT tumours and the other to p53 tumours (Additional file 6: Figure S4). 
To further refine the list of sites upregulated in a particular tumour type versus the other two, an analysis of variance (ANOVA)-based approach was implemented. Thirty-two pY sites were upregulated in HER2 tumours, eighty-six in p53 tumours and eighty in PyMT tumours (Additional file 5: Table S2). Of note, certain proteins exhibited site-selective variation in phosphorylation between different tumour types, examples being Tln1 and Cbl. Elevated levels of Erbb3 pY1325 and p85 pY467 in PyMT tumours were confirmed by Western blot analysis with appropriate phosphospecific antibodies (Additional file 7: Figure S5). Immunoblotting for selected targets revealed that, for certain $\mathrm{pY}$ sites characteristic of a given subtype, elevated phosphorylation was accompanied by increased expression of the given protein. This was exemplified by Irs1 and Pik3r1 (p85) in PyMT tumours (Figure 2A and B). However, for others, the increased phosphorylation must reflect a change in relative phosphorylation, as for Erbb3 in PyMT tumours, Cdk16 in p53 tumours and Erffi1 in HER2 tumours (Figure 2C to E). References for the sites characterised in this figure are provided in PhosphoSite [49].

We also developed and applied a random forest classifier to identify 17 highly variable pY sites that can be used to distinguish between the tumour types (Figure 3). Amongst these, elevated phosphorylation of Pik3r1, Pik3r3, a $G$ protein-coupled receptor (Gprc5c) and an uncharacterised protein (2310030G06Rik) was specific to PyMT tumours, and p53 tumours were characterised by increased phosphorylation of Vim, Ptrf, Vcl, Fgr, Met and a protein related to heat shock protein $70 \mathrm{kDa}$. Elevated tyrosine phosphorylation of Errfil characterised HER2 tumours.

\section{Pathway and protein-protein interaction analysis}

Lists of pY sites enriched in each tumour type were then subjected to bioinformatics analysis to identify associated pathways or biological processes (Table 1). Strikingly, marked differences were observed between p53, HER2 and PyMT tumours. The former exhibited an enrichment of processes linked to cytoskeletal reorganisation, with the top five significant terms being leucocyte transendothelial migration, bacterial invasion of epithelial cells, regulation of actin cytoskeleton, focal adhesion and muscle contraction. The only term significantly enriched for HER2 tumours was the ErbB signalling pathway, whereas the PyMT tumours were characterised by processes involving PI3K signalling, including type 2 diabetes mellitus, the FceRI signalling pathway, acute myeloid leukaemia, Fcy receptor-mediated phagocytosis and the neurotrophin signalling pathway.

Significantly upregulated pY sites (determined by ANOVA) characteristic of each tumour type were analysed using PINA [37,38] (Figures 4, 5 and 6). Where available, consensus lists were searched against mouse data sets containing previously reported interaction data; however, in cases where interactions were not reported in mouse data sets, human orthologues were used to model potential interactions. In addition, kinase substrate relationships were extracted from PhosphoSitePlus [39]. A key characteristic of p53 tumours was the presence of a major protein-protein interaction hub composed of several proteins involved in cytoskeletal organisation (Actn1, Actn4, Sept7, Sept 9 and Plec), as well as a further hub centred on Itgb1 (Figure 4). The latter involved numerous proteins localised to focal adhesions, including Bcar1, Tln1, Pxn and Vcl. These findings are in agreement with the corresponding pathway analysis (Table 1). Furthermore, there are notable similarities between this network and that present in human basal and claudin-low breast cancer cell lines [16], including increased tyrosine phosphorylation of Met, Cav1, Bcar1 and Tln1. This is consistent with previous reports that subsets of p53 tumours exhibit gene expression signatures characteristic of these breast cancer subgroups [21,22]. In contrast, HER2 tumours exhibited a protein-protein interaction network that reflected the relationship between HER2 and its associating substrates (for example, Cbl, Ptpn11, Plc 1 ), but it is noteworthy that Egfr and Pdgfra, as well as the feedback inhibitor Errfil, are also components of this network (Figure 5). Consistent with the pathway analysis, PyMT tumours exhibit a major interaction hub that centres on the PI3K regulatory subunit Pik3r1 (Figure 6). Interestingly, in addition to PyMT itself, this hub involves two RTKs (Kit and Erbb3) and two docking proteins (Irs1 and Gab1) that are well-characterised binding partners for Pik3r1. Although Src is required for efficient induction of mammary tumours by PyMT [50], increased phosphorylation of Y416 on the Src activation loop (a peptide sequence conserved amongst SFKs) or Src-selective peptides was not detected in PyMT tumours. However, three additional SFKs-Yes, Lyn and Hck-exhibited increased phosphorylation on unique peptide sequences and resided within the network (Figure 6). The former is known to interact with PyMT [19] but is not essential for PyMTinduced mammary tumourigenesis [50].

\section{Subclassification of p53 tumours}

In a previous study on the Tp53-null mouse mammary tumour model, researchers demonstrated that the generated tumours exhibit considerable heterogeneity and can be classified by transcript profiling into a variety of molecular subtypes, including one luminal, one claudin-low and two basal-like subtypes [22]. To interrogate this potential heterogeneity at the level of tyrosine phosphorylation patterns, we undertook unsupervised hierarchical clustering of the p53 tumours based on all phosphorylation sites detected in these tumours (Additional file 8: Figure S6). Tumours 1203 and 1204 clustered together and were characterised by markedly elevated (greater than tenfold) 


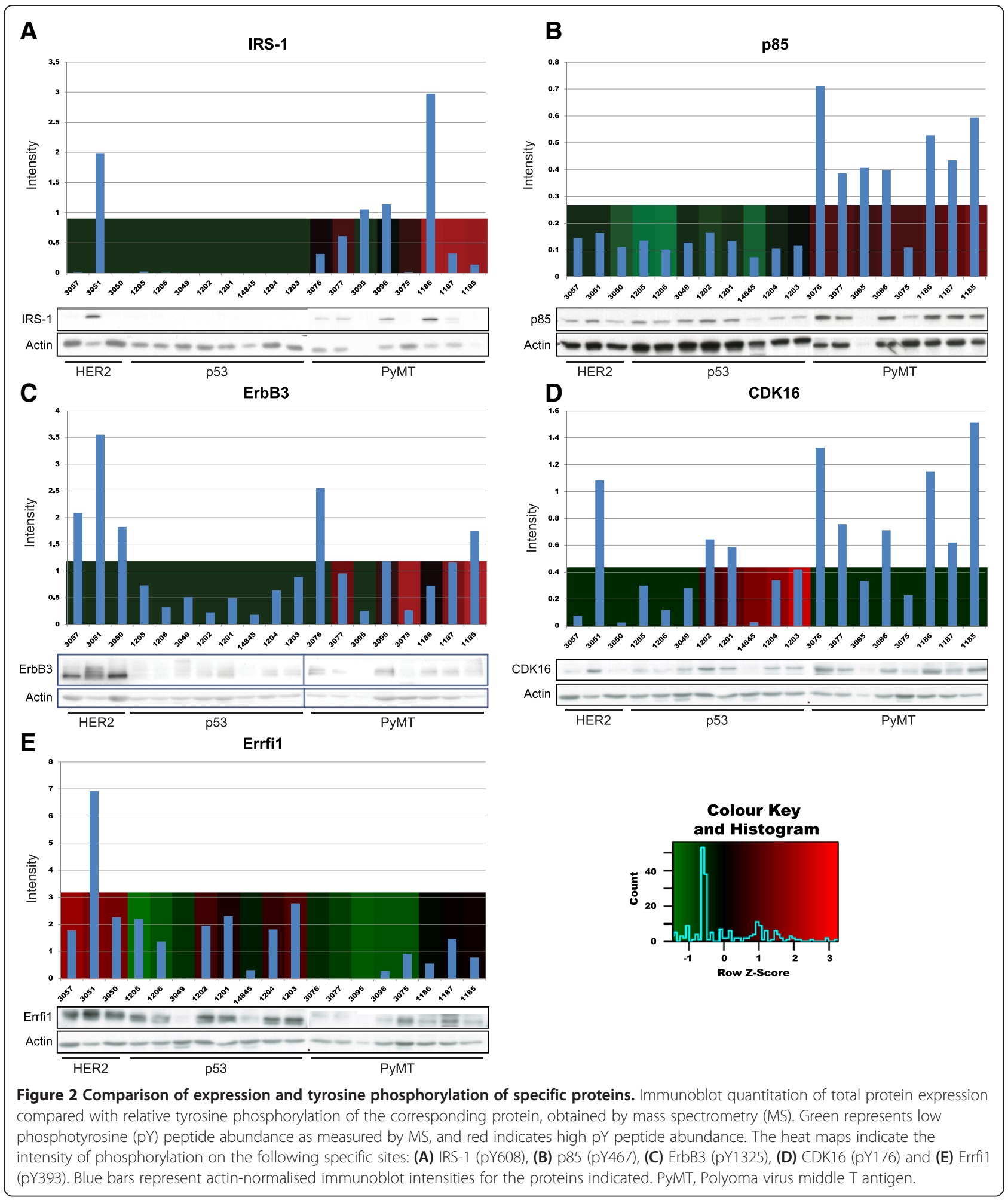

tyrosine phosphorylation of approximately 100 proteins compared to the remainder of p53 tumours (Additional file 9: Table S3). Tumour 14845 also exhibited relatively high tyrosine phosphorylation of many proteins, but not to the same extent as tumours 1203 and 1204, and tumours 3049, 1201 and 1202 displayed elevated phosphorylation of more distinct protein subsets. Tumours 1205 and 1206 were characterised by relatively low levels of tyrosine phosphorylation. Hypothesizing that the extremely high levels of tyrosine phosphorylation in tumours 


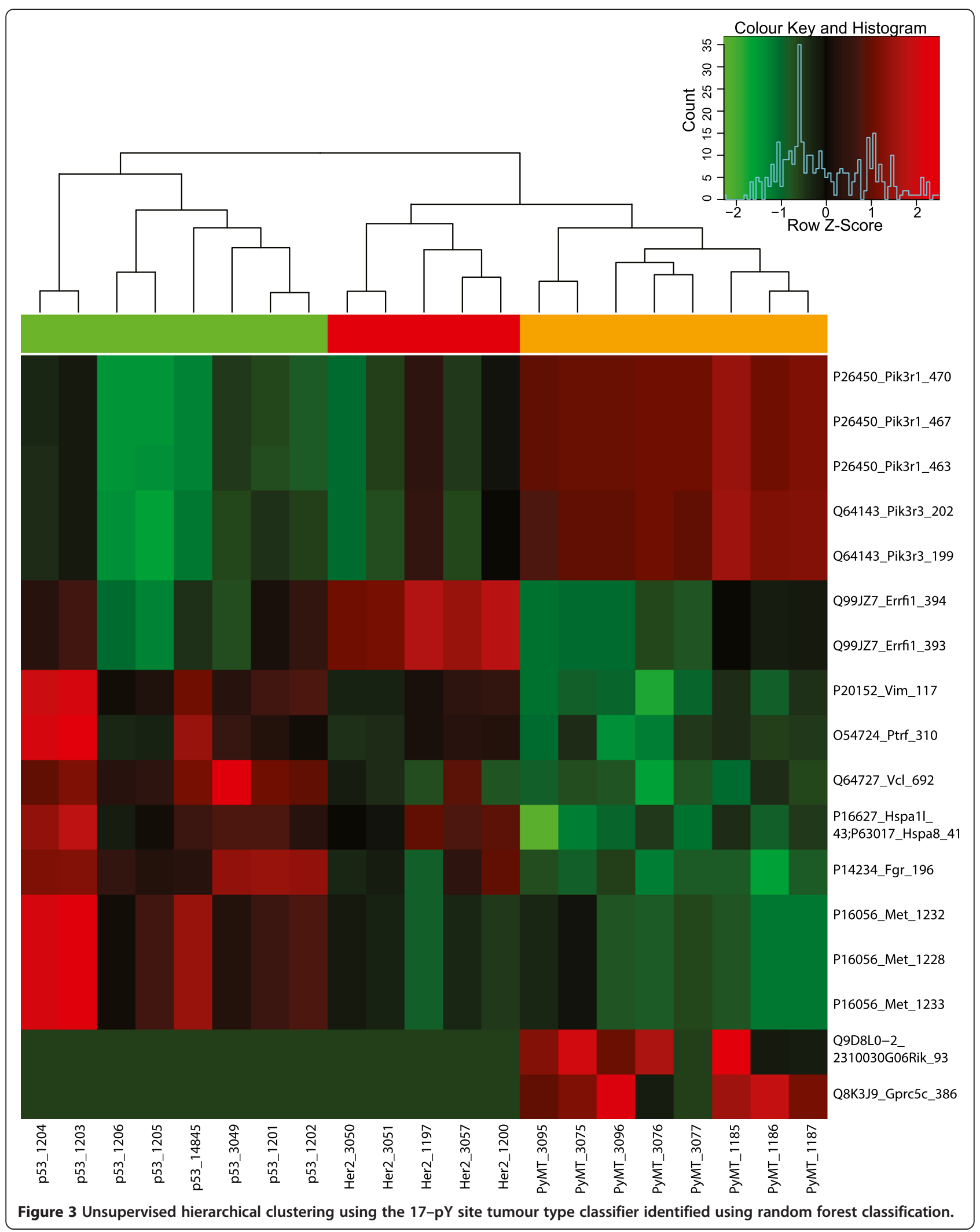


Table 1 Top ten pathways/biological processes for each tumour type ${ }^{a}$

\begin{tabular}{|c|c|c|c|}
\hline Term & $\begin{array}{l}\text { Corrected } \\
P \text {-value }\end{array}$ & Accession & Gene name \\
\hline \multicolumn{4}{|l|}{ p53 } \\
\hline $\begin{array}{l}\text { Leucocyte transendothelial } \\
\text { migration }\end{array}$ & 7.87E-05 & $\begin{array}{l}\text { P70460|Q61 140|P26040|P26041|Q64727|Q8VI36|P57780| } \\
\text { Q7TPR4|P09055 }\end{array}$ & Vasp|Bcar1|Ezr|Msn|Vcl||Pxn|Actn4|Actn1||tgb1 \\
\hline $\begin{array}{l}\text { Bacterial invasion of } \\
\text { epithelial cells }\end{array}$ & $<0.01$ & P22682|Q61 140|Q64727|Q8VI36|Q9JM76|P49817|P09055 & Cbl|Bcar1|Vc||Pxn|Arpc3|Cav1||tgb1 \\
\hline $\begin{array}{l}\text { Regulation of actin } \\
\text { cytoskeleton }\end{array}$ & $<0.01$ & $\begin{array}{l}\text { Q61 140|P26040|P26041|Q7TPR4|Q64727|Q8VI36|P26043| } \\
\text { P57780|Q9JM76|P09055 }\end{array}$ & Bcar1|Ezr|Msn|Actn1|Vc||Pxn|Rdx|Actn4|Arpc3||tgb1 \\
\hline Focal adhesion & $<0.01$ & $\begin{array}{l}\text { P70460|P26039|Q61 140|Q64727|Q8VI36|P57780|Q7TPR4| } \\
\text { P49817|P09055 }\end{array}$ & Vasp|TIn1|Bcar1|Vc||Pxn|Actn4|Actn1|Cav1||tgb1 \\
\hline Muscle contraction & $<0.01$ & P62204|Q64727|P20152|Q8VI36|P26039 & Calm1|Vcl|Vim|Pxn|TIn1 \\
\hline Haemostasis & $<0.01$ & $\begin{array}{l}\text { P12023|P20491|P26039|Q61 140|Q91Y|4|P14234|P48025| } \\
\text { P57780|Q7TPR4|P49817|P09055 }\end{array}$ & $\begin{array}{l}\text { App|Fcer1g|TIn1|Bcar1|Arrb2|Fgr|Sykb|Actn4|Actn1| } \\
\text { Cav1||tgb1 }\end{array}$ \\
\hline $\begin{array}{l}\text { Fcy receptor-mediated } \\
\text { phagocytosis }\end{array}$ & 0.02 & Q9JM76|P70460|P08103|Q9ES52|P48025 & Arpc3|Vasp|Hck||npp5d|Sykb \\
\hline Adherens junction & 0.05 & Q9D358|P57780|Q7TPR4|Q64727 & Acp1|Actn4|Actn1|Vcl \\
\hline Cell-cell communication & 0.05 & Q80W68|Q9QXS1|Q7TPR4|P09055|Q3UND0 & Kirrel|Plec|Actn1||tgb1|Skap2 \\
\hline Endocytosis & 0.12 & P22682|Q91Y14|P01899|Q99LI8|Q62351|P49817 & Cbl|Arrb2|H2-D1|Hgs|Tfrc|Cav1 \\
\hline \multicolumn{4}{|l|}{ Her2 } \\
\hline ErbB signalling pathway & $3.79 \mathrm{E}-02$ & P70424|Q01279|P47941|P22682|Q62077 & Erbb2|Egfr|Crk||Cb||Plcy1 \\
\hline Disease & 0.09 & Q99LI8|P35235|Q01279|P22682|Q62077 & Hgs|Ptpn11|Egfr|Cb||Plcy1 \\
\hline Non-small-cell lung cancer & 0.16 & P70424|Q01279|Q62077 & Erbb2|Egfr|Plcy1 \\
\hline Pathways in cancer & 0.16 & P22682|Q62077|P47941|Q01279|P26618|P70424|P97807 & Cbl|Plcү1|Crk||Egfr|Pdgfra|Erbb2|Fh1 \\
\hline Glioma & 0.16 & Q62077|Q01279|P26618 & Plcy1|Egfr|Pdgfra \\
\hline Focal adhesion & 0.16 & P70424|Q01279|P47941|P26039|P26618 & Erbb2|Egfr|Crk||Tln1|Pdgfra \\
\hline Renal cell carcinoma & 0.16 & P35235|P47941|P97807 & Ptpn11|Crk||Fh1 \\
\hline $\begin{array}{l}\text { Neurotrophin signalling } \\
\text { pathway }\end{array}$ & 0.16 & O08911|P35235|P47941|Q62077 & Mapk12|Ptpn11|Crk||PlCy1 \\
\hline Chronic myeloid leukaemia & 0.16 & P35235|P47941|P22682 & Ptpn11|Crk||Cbl \\
\hline Developmental biology & 0.16 & P35235|P70424|Q01279|P26039|Q62077 & Ptpn11|Erbb2|Egfr|TIn1|Plcy1 \\
\hline \multicolumn{4}{|l|}{ РyMT } \\
\hline Type 2 diabetes mellitus & $3.08 \mathrm{E}-02$ & P35569|Q64143|Q63844|P26450|P28867 & Irs1|Pik3r3|Mapk3|Pik3r1|Prkcd \\
\hline FceRI signalling pathway & 0.03 & P28867|Q63844|P25911|Q64143|Q9Z1B7|P26450 & Prkcd|Mapk3|Lyn|Pik3r3|Mapk13|Pik3r1 \\
\hline Acute myeloid leukaemia & 0.03 & Q64143|Q63844|P05532|P26450|P42227 & Pik3r3|Mapk3|Kit|Pik3r1|Stat3 \\
\hline $\begin{array}{l}\text { Fcy receptor-mediated } \\
\text { phagocytosis }\end{array}$ & 0.04 & P28867|Q63844|P08103|Q64143|P25911|P26450 & Prkcd|Mapk3|Hck|Pik3r3|Lyn|Pik3r1 \\
\hline $\begin{array}{l}\text { Neurotrophin signalling } \\
\text { pathway }\end{array}$ & 0.04 & $\begin{array}{l}\text { P35569|P28867|Q63844|Q64143|Q9Z1B7|Q9QYY0| } \\
\text { P26450 }\end{array}$ & Irs1|Prkcd|Mapk3|Pik3r3|Mapk13|Gab1|Pik3r1 \\
\hline $\begin{array}{l}\text { Aldosterone-regulated } \\
\text { sodium reabsorption }\end{array}$ & 0.04 & P35569|Q64143|Q63844|P26450 & Irs1|Pik3r3|Mapk3|Pik3r1 \\
\hline ErbB signalling pathway & 0.09 & Q9QYY0|Q63844|P26450|Q61526|Q64143 & Gab1|Mapk3|Pik3r1|Erbb3|Pik3r3 \\
\hline Cell-cell communication & 0.10 & Q80W68|P30999|P26450|Q9Z1B7 & Kirrel|Ctnnd1|Pik3r1|Mapk13 \\
\hline Hepatitis C & 0.10 & Q63844|Q9Z0G9|Q64143|Q9Z1B7|P42227|P26450 & Mapk3|Cldn3|Pik3r3|Mapk13|Stat3|Pik3r1 \\
\hline $\begin{array}{l}\text { Chemokine signalling } \\
\text { pathway }\end{array}$ & 0.12 & P28867|Q63844|P08103|Q64143|P42227|P25911|P26450 & Prkcd|Mapk3|Hck|Pik3r3|Stat3|Lyn|Pik3r1 \\
\hline
\end{tabular}

aPyMT: Polyoma virus middle T antigen. Significantly enriched terms are shown in bold. 


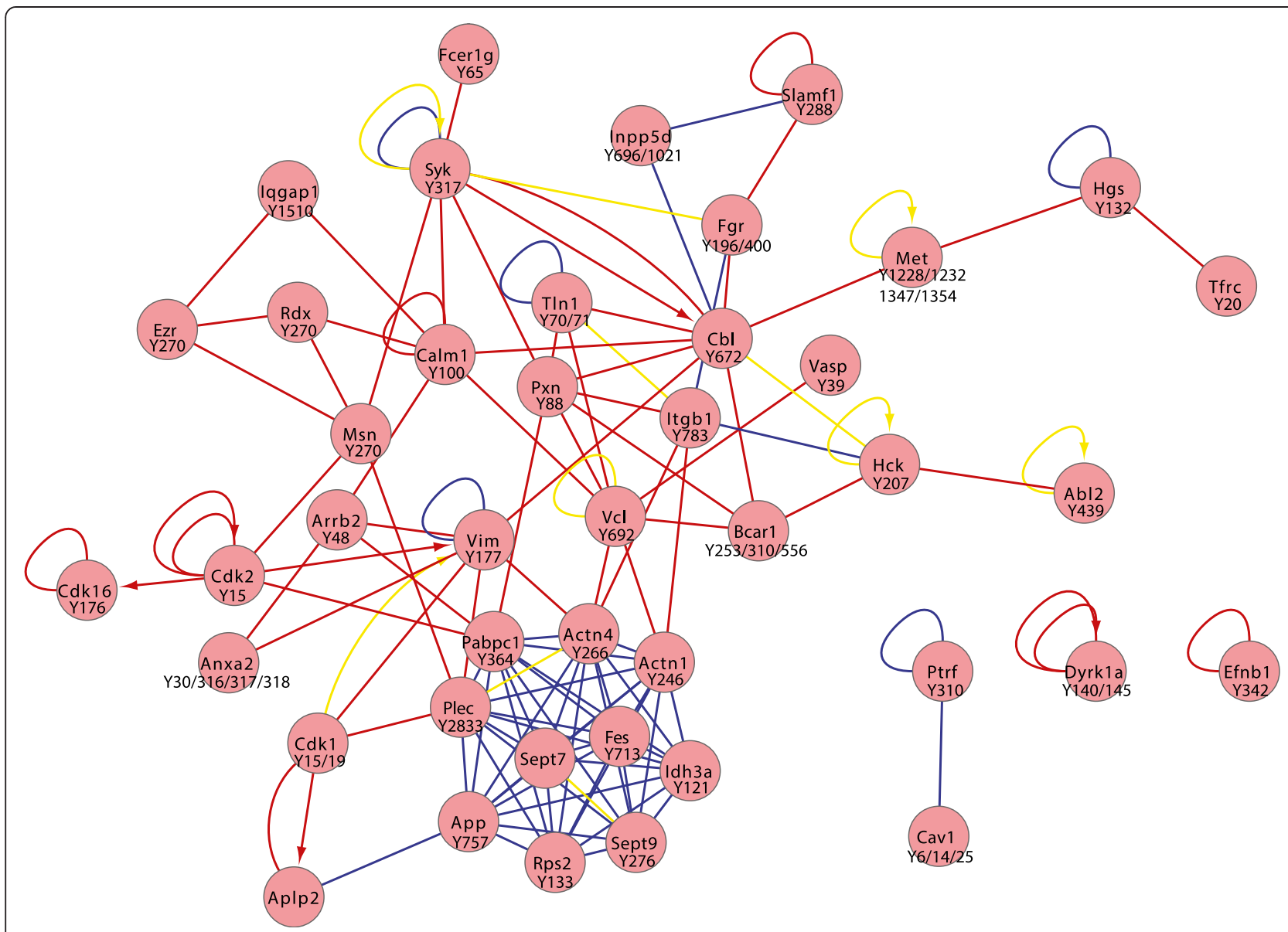

Figure 4 Protein Interaction Network Analysis of proteins exhibiting significantly enhanced tyrosine phosphorylation in the p53

tumour model. The direct protein-protein interactions are indicated by lines, with blue and red lines representing data from mouse and human orthologue databases, respectively. Interactions that have been described previously in both human and mouse are indicated by yellow lines. Kinase substrate relationships are indicated by arrows.
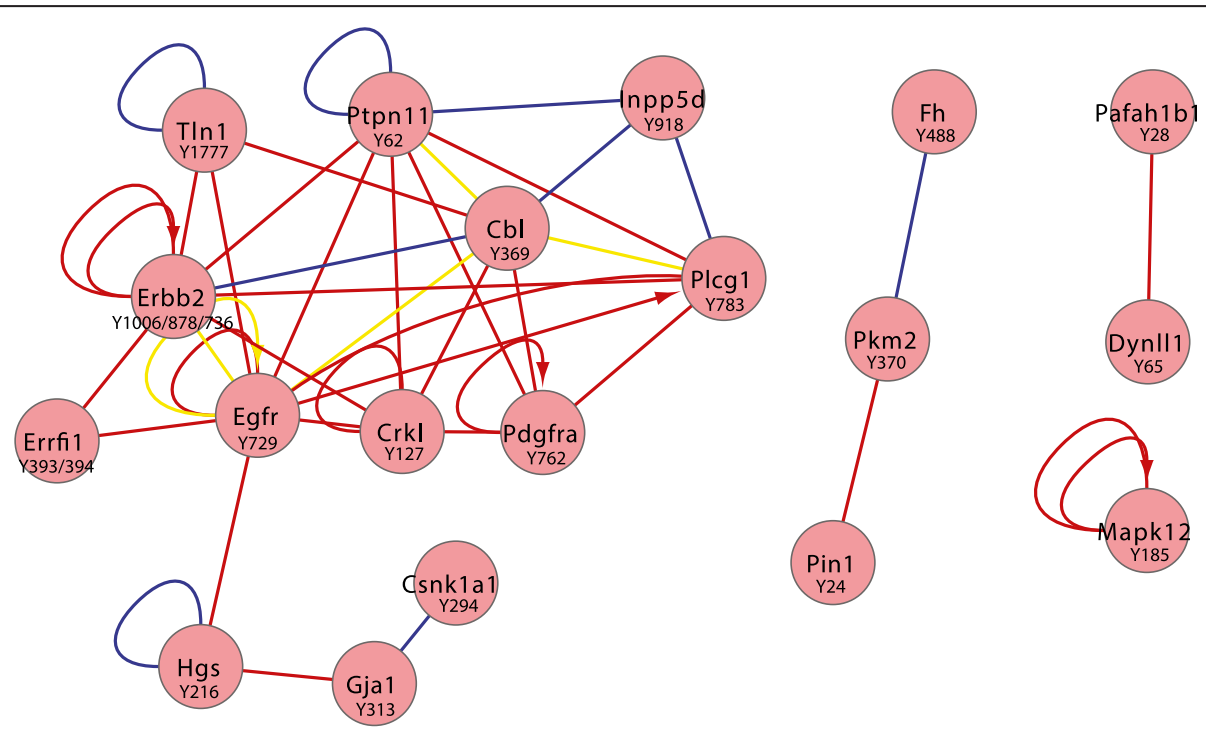

Figure 5 Protein Interaction Network Analysis of proteins exhibiting significantly enhanced tyrosine phosphorylation in the Her2 tumour model. The protein-protein interactions are indicated as described for Figure 4. 


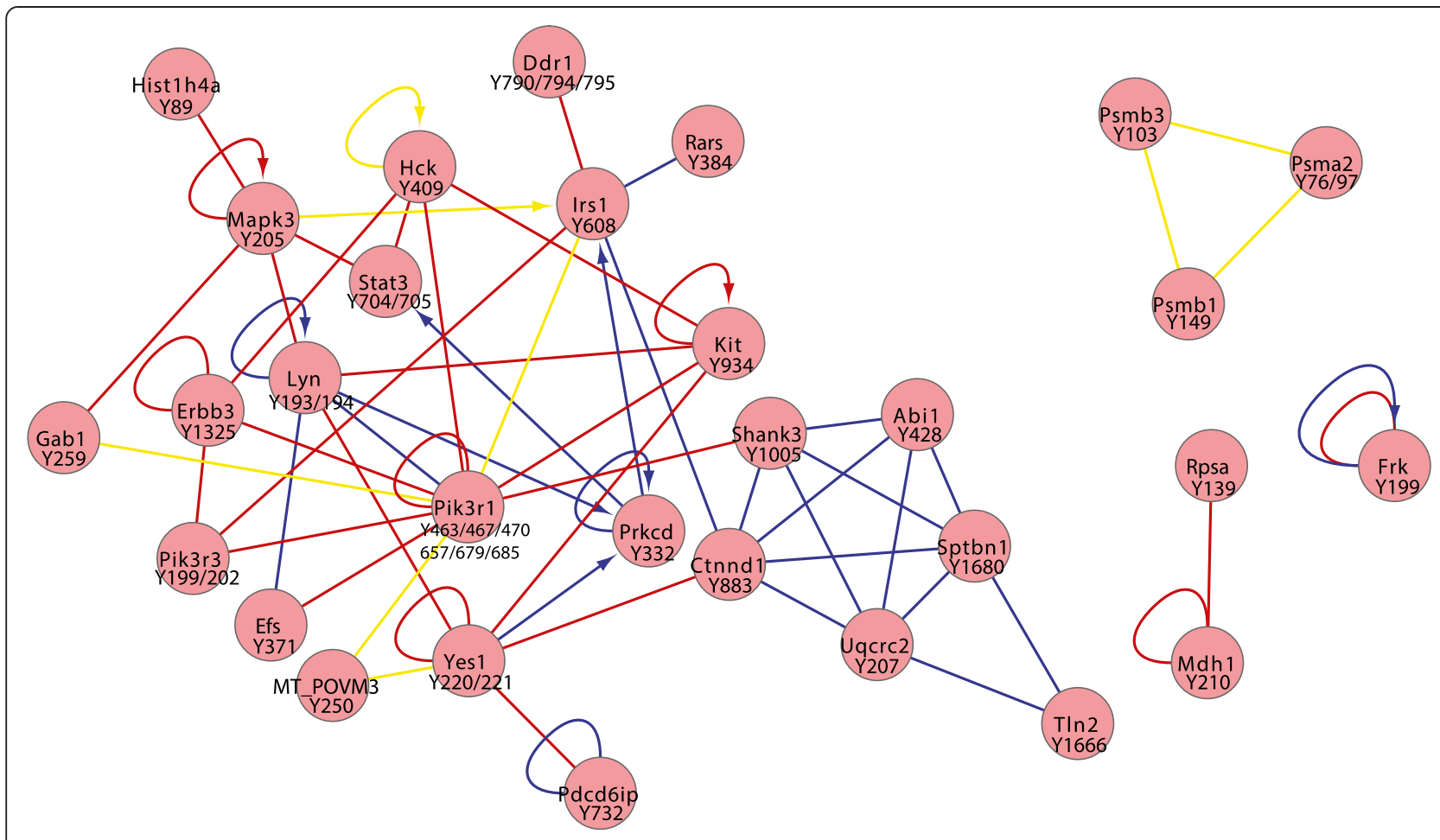

Figure 6 Protein Interaction Network Analysis for proteins exhibiting significantly enhanced tyrosine phosphorylation in the polyoma virus middle T antigen tumour model. The protein-protein interactions are indicated as described for Figure 4.

1203 and 1204 might reflect upregulation of a particular tyrosine kinase in these two tumours, we noted that several of the upregulated $\mathrm{pY}$ sites were from Met, specifically Y1228, Y1232, Y1233, Y1347 and Y1354 (Figure 7). In addition, Y6 and Y14 on Cav1 also exhibited increased phosphorylation, which was of interest, given the close proximity of the Met and Cav1 genes on mouse chromosome 6 and coamplification of these two genes in particular tumour types [51-53]. Immunoblotting for Met and Cav1 revealed markedly increased total protein expression in the p53 samples from tumours 1203 and 1204 (Figure $8 \mathrm{~A}$ and $\mathrm{B}$ ). In addition, aCGH was performed on the p53 tumours. This revealed that, though p53 tumours 1201, 1205, 1206 and 14845 exhibited small (two- to threefold) increases in copy number for regions of chromosome 6 harbouring Met and Cav1, tumours 1203 and 1204 displayed 20- and 25-fold amplifications, respectively, of a chromosomal segment spanning these two genes (Figure 8C and D and Additional file 10: Table S4).

Having demonstrated that tumours 1203 and 1204 are characterised by Met gene amplification, we compared the tyrosine phosphorylation profile of these two tumours versus the other p53-null tumours in more detail. Consistent with enhanced Met signalling, tyrosine phosphorylation of Hgs, which regulates Met endocytic trafficking [54], was markedly elevated (Additional file 9:
Table S3). These tumours were also characterised by increased tyrosine phosphorylation of Ptrf/cavin, which is localised with Cav1 to caveolae, and of the RTK Axl and the docking protein Dock1 (Additional file 9: Table S3). Interestingly, pathway analysis revealed that tumours 1203/1204 demonstrated significant enrichment for the term glycolysis/gluconeogenesis, reflecting increased tyrosine phosphorylation of several metabolic enzymes, including Pgam1, Pkm2 and Pgk1 (Additional file 11: Table S5).

To gain insight into the functional role of Met in the p53 tumours, we established cell lines from tumours 1201 and 1206 (low-level Met gene amplification) and tumour 1204 (high-level Met amplification). Pretreatment of these cell lines with the Met TKI PHA-665752 decreased Met phosphorylation on Y1234/Y1235 and markedly reduced the elevated cellular tyrosine phosphorylation levels in tumour 1204 cells (Figure 9A). Importantly, though administration of the Met TKI at a concentration $(1 \mu \mathrm{M})$ that ablated Met tyrosine phosphorylation had no effect on proliferation in tumour 1201 cells (Figure 9B), this treatment markedly attenuated proliferation of tumour 1204 cells (Figure 9C). As an alternative and complementary approach, we knocked down Met expression using selective siRNAs (Additional file 12: Figure S7). Met knockdown had only a modest effect in the 1201 and 1206 tumour cell lines, but markedly attenuated proliferation in 


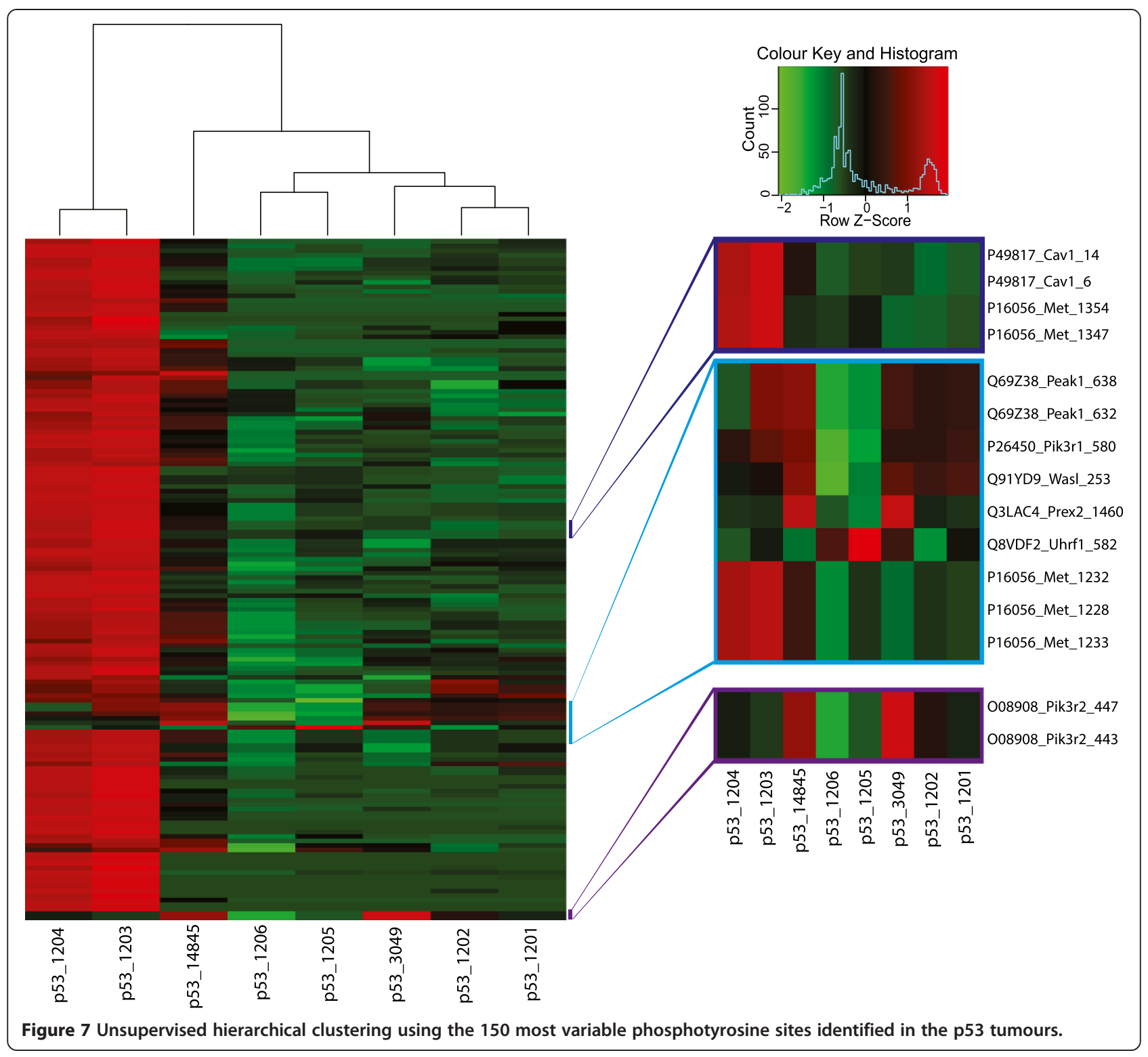

the 1204 tumour cell line with high-level Met amplification $(P<0.005$ for comparisons of Met knockdowns in the 1201 or 1206 tumour cell line versus the 1204 tumour cell line). These data indicate that the extremely high levels of tyrosine phosphorylation detected in tumour 1204 (Figure 7) are dependent on Met activity, and that cells from these tumours are addicted to Met activation for their proliferation in vitro.

Interrogation of the tyrosine phosphorylation patterns characteristic of the other p53-null subgroups revealed that phosphorylation of the atypical kinase Peak1/SgK269 [55] was elevated in tumour 14845 and to a lesser extent the subgroup containing 3049, 1202 and 1201, whereas phosphorylation of Prex2 characterised tumours 14845 and 3049, where it was accompanied by enhanced phosphorylation of Pik3r2 (Figure 7). Taken in association with our demonstration of Met amplification in tumours 1203 and 1204, these findings highlight the power of tyrosine phosphorylation profiling to identify candidate oncogenic drivers [56].

\section{Discussion}

Specific genetically modified mouse models of breast cancer have made major contributions to our understanding of the role of particular oncogenes in the development of this malignancy [18]. In addition, characterisation of tumours arising in these models by approaches such as transcript profiling and aCGH have identified molecular aberrations conserved between mouse and human mammary tumours that are likely to represent key 'driver' events [21,22,57]. However, to date, no comprehensive characterisation of the tyrosine kinase signalling networks 


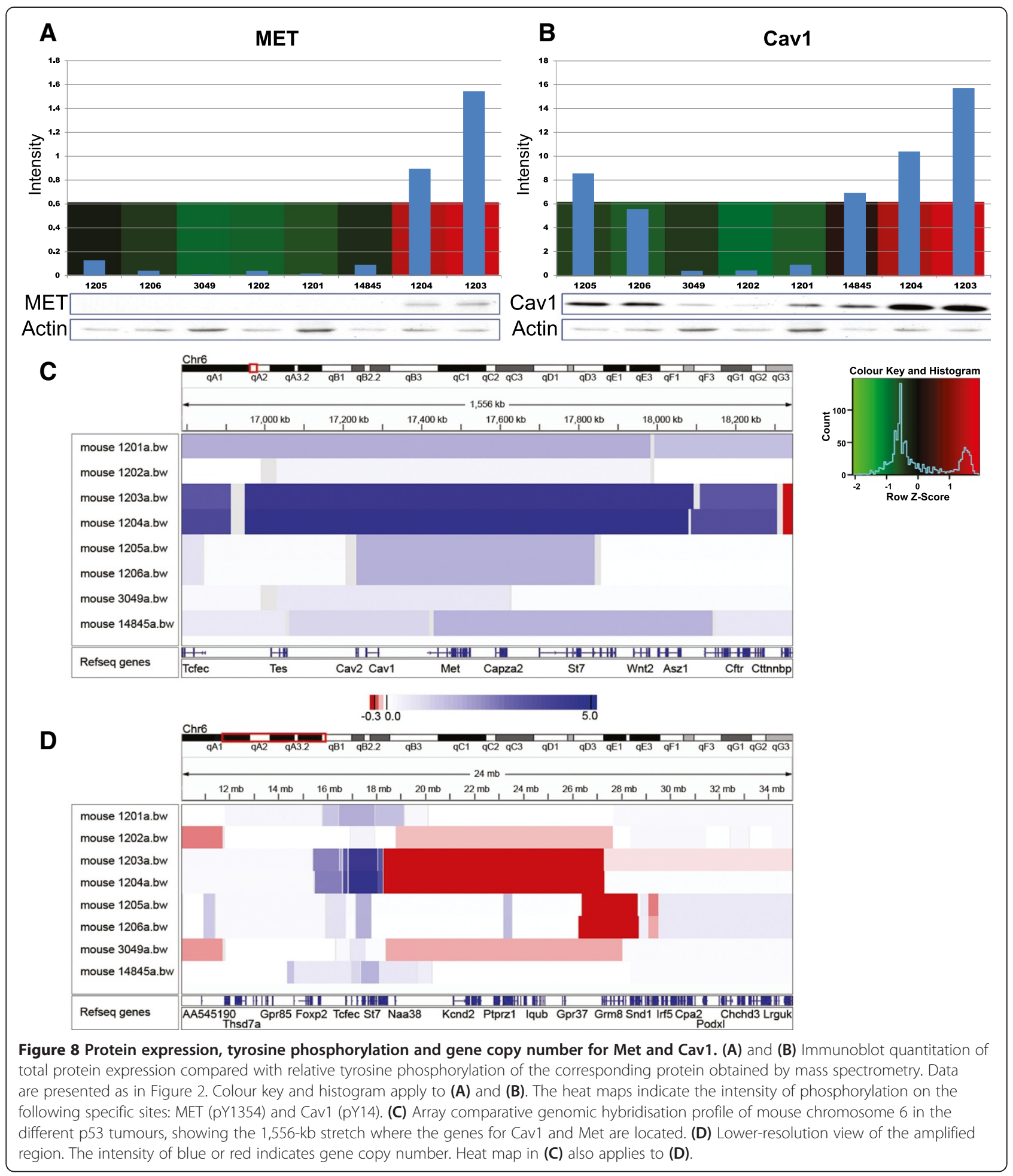

present in such models has yet been undertaken. In this study, we used MS-based global tyrosine phosphorylation profiling to characterise three commonly used mouse models of breast cancer, which revealed distinct differences between these models and features conserved with subtypes of the human disease.
For an erbB2 model, we used a truncated form of Neu $[26,27]$ that models a form of erbB2 lacking the extracellular domain present in approximately 30\% of HER2-positive breast cancer patients, for whom it is associated with a worse prognosis [58]. This form exhibits potent oncogenic activity [59]. These tumours were characterised by 


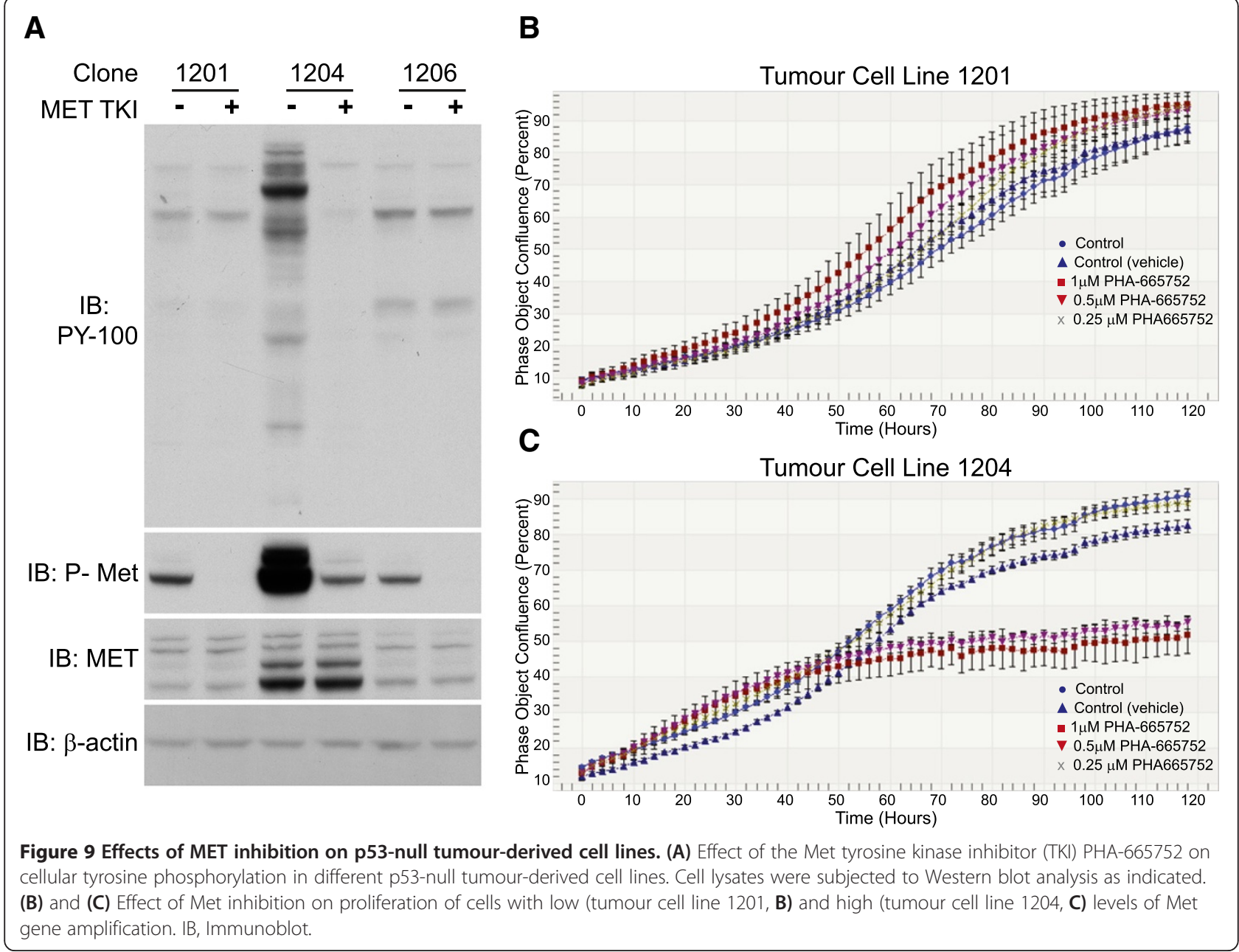

increased phosphorylation of several signalling molecules known to associate with erbB2, including Ptpn11, Plcy1, $\mathrm{Cbl}$ and $\mathrm{CrkL}$, as well as its heterodimerisation partner Egfr. Given the known heterodimerisation of full-length erbB2 and erbB3, our finding that phosphorylation of erbB3 Y1325 was not elevated in the majority of HER2 tumours (expressing truncated neu), despite increased erbB3 expression (Figure 2), is surprising and warrants further investigation in cell culture models and clinical specimens. Additional novel findings include enhanced tyrosine phosphorylation of Errfil and Pdgfro. The former represents a negative feedback regulator of erbB signalling that inhibits EGFR and erbB2 kinase activity by binding directly to the receptor kinase domain and blocking the formation of the activating dimer interface [60]. However, although increased expression of Errfil is associated with high erbB receptor signalling [61], expression of Errfi1 was similar between HER2 and p53 tumours, indicating that it is the relative tyrosine phosphorylation of Errfil on Y393/Y394 that is altered. Importantly, phosphorylation of Errfil on Y394 reduces its ability to inhibit Egfr [62], indicating that this modification may act to attenuate negative regulation of HER2 signalling by Errfil in these tumours. Consequently, it will be of great interest to determine how expression of Errfil, and also its tyrosine phosphorylation, relate to HER2 expression and outcome in breast cancer patients.

The finding of increased Pdgfra phosphorylation is of interest because autocrine Pdgf action is associated with TGF- $\beta$-induced epithelial-mesenchymal transition (EMT) in MMTV-Neu mammary tumours and because increased Pdgfra and Pdgfr $\beta$ expression occur in late-stage, invasive human breast cancers [63]. Researchers in a previous study demonstrated that a truncated form of HER2, similar to that used in this study, specifically induced the expression of a set of genes involved in cancer cell spread and associated with poor patient prognosis [59]. Thus, the induction of Pdgfra signalling in our model may reflect the oncogenic potency of the truncated form of Neu utilised and the occurrence of EMT.

A previous study on the PyMT model revealed a dependence on PI3K activation for efficient tumourigenesis 
[20]. Although that finding was revealed by mutation of the p85 binding sites on PyMT [20], our pathway and protein-protein interaction analyses on the tyrosine-phosphorylated proteins selectively enriched in these tumours also support a key role for PI3 kinase signalling in this tumour type. These results highlight the presence of other p85 binding proteins in these tumours in addition to PyMT itself, including erbB3, Gab1 and Irs1. All of the latter three proteins have been characterised as positive regulators of PI3K signalling [64]. In addition, enhanced tyrosine phosphorylation of p85a on several sites was detected in these tumours. Tyrosine phosphorylation of p85a on Y688 has been reported to relieve its inhibitory activity on PI3K [65]; however, we did not detect phosphorylation on this site in our present study, and the functional role of the p85a phosphorylation events enhanced in PyMT tumours requires further characterisation.

An important question is the identity of the tyrosine kinases driving PyMT tyrosine phosphorylation. It is well established that PyMT associates with, and is phosphorylated by, the SFKs Src and Yes, and also that expression of Src is essential for efficient PyMT-induced tumourigenesis $[19,50]$. However, in a recent article, researchers reported that PyMT associates with the RTK erbB2 and the catalytically impaired erbB3 and that both erbB2 activity and erbB3 expression are essential for PyMT transforming activity [66]. These data, together with those published by the Muller group [50], indicate that erbB2 may act upstream of Src in this model. However, we could detect only erbB3derived, and not erbB2-derived, tyrosine-phosphorylated peptides in the majority of PyMT tumours. A potential explanation is that one or more RTKs may substitute for erbB2 in this model. Because Egfr phosphorylation was detected and phosphorylation of Kit was enhanced in this tumour type, these RTKs represent potential candidates.

The p53 tumour model exhibits heterogeneity at the histological and gene expression levels, and, on the basis of the latter parameter, can be classified into different molecular subgroups, including basal-like, claudin-low and luminal subtypes [22]. Although we profiled only eight p53 tumours, our data are consistent with the ability of this model to generate tumours with a basal or claudinlow phenotype. First, there was notable overlap between the identified signalling networks in these tumours and basal and claudin-low breast cancer cells [16]. Second, tyrosine-phosphorylated proteins characteristic of p53 tumours exhibited an enrichment for pathways associated with cytoskeletal organisation, in concordance with the observed mutational spectrum reported for triple-negative breast cancers [67]. Third, two of the p53 tumours exhibited markedly enhanced tyrosine phosphorylation of many cellular proteins, including Met, and this was associated with high-level amplification of a segment of chromosome 6 that contains the Met and Cav1 genes. This is consistent with high expression and amplification of the MET gene in human basal breast cancers $[13,15,68]$ and amplification of the Met/Cav1 locus in basal-like mammary tumours in mice with mammary-specific deletion of Lfng [52]. In addition, researchers in a recent study demonstrated that transgenic Met overexpression in the mouse mammary gland cooperates with conditional p53 loss to drive the formation of claudin-low mammary tumours, and they showed that claudin-low tumours developing in mice without the MMTV-Met transgene and only conditional mammary gland-specific deletion of p53 exhibited amplification of the endogenous Met gene [69]. These data are in concordance with our data demonstrating Met amplification in a subset of p53-null mammary tumours and highlight the potential utility of transplantable tumours 1203 and 1204 and the MMTV-Met ${ }^{\mathrm{mt}} ; \operatorname{Trp} 53 \mathrm{fl} /+$;Cre model generated by the Park group [69] as preclinical models in which to test Met-directed therapies for triple-negative breast cancer. Indeed, our data indicate that p53-null cells with high-level Met amplification are dependent on Met activation for their continued proliferation.

Our finding that tumours 1203 and 1204 demonstrated increased tyrosine phosphorylation of several enzymes involved in glycolysis and gluconeogenesis indicates that this tumour subset is likely to exhibit altered metabolic properties. Indeed, tyrosine phosphorylation of both $\mathrm{Pkm} 2$ Y105 and Pgam1 Y26 regulates their activity and, by modulating aerobic glycolysis and anabolic biosynthesis, promotes tumourigenesis [70,71]. In light of these findings, it will be important to determine whether MET-amplified human breast cancers exhibit corresponding metabolic changes and whether the altered metabolism confers an 'Achilles heel' amenable to therapeutic intervention.

The identification of two p53 tumours exhibiting Met gene amplification highlights how mouse models of mammary tumourigenesis can be used to identify breast cancer oncogenic 'drivers'. Of note, our phosphoproteomic profiling of p53 tumours identified markedly enhanced tyrosine phosphorylation of Peak1/SgK269 and Prex2 in other p53-null tumour subsets. The former protein is an atypical kinase recently demonstrated to exhibit characteristics of a breast cancer oncogene, and site-selective Peak1/SgK269 tyrosine phosphorylation promotes biological activity [55]. Prex2 is a negative regulator of PTEN (phosphatase and tensin homologue) and is mutated in melanoma [72], although the role of Prex2 tyrosine phosphorylation is yet to be determined. Consequently, these two proteins represent strong candidates for further functional characterisation and evaluation as therapeutic targets and biomarkers.

\section{Conclusions}

Our finding that three commonly utilised mouse models of breast cancer are characterised by distinct tyrosine 
phosphorylation-based signalling networks provides important insights into mechanisms of mammary tumour development and progression. The identification of Met as an oncogenic driver in a subset of p53-null tumours highlights how comparative phosphoproteomics can identify conserved oncogenic signalling pathways and identifies a new preclinical model for a subset of triplenegative breast cancers.

\section{Additional files}

Additional file 1: Figure S1. (A) The lineage of the different tumour samples characterised. (B) Clustering relationships in comparison to tumour of origin for the xenografts. The coloured lines indicate which tumour transplants share a common origin. The coloured ovals indicate instances where only one transplant tumour from a particular clonal line was characterised.

Additional file 2: Table S1. $763 \mathrm{pY}$ sites identified from the pY profiling of p53, Her2 and PyMT mammary mouse tumours.

Additional file 3: Figure S2. (A) Gene Ontology annotation of the phosphoproteins identified from the three mouse tumour models. (B) Proportion of different kinase types identified (based on number and subclassification). (C) Contribution of different non-receptor tyrosine kinases, based on pY peptide spectral intensity. (D) Contribution of different receptor tyrosine kinases based on pY peptide spectral intensity.

Additional file 4: Figure S3. Unsupervised hierarchical clustering using all 763 identified pY sites. (Imputation: $k$-NN + column mean).

Additional file 5: Table S2. 381 highly reproducible pY sites. Additional file 6: Figure S4. Unsupervised hierarchical clustering using the $381 \mathrm{pY}$ sites detected in at least $75 \%$ of one tumour type. (Imputation: $k-\mathrm{NN}+$ row min)

Additional file 7: Figure S5. (A) and (B) Immunoblot quantitation of phosphorylation on specific phosphosites compared with relative tyrosine phosphorylation on the same sites determined by MS. Data are presented as in Figure 2, and colour key and histogram apply to (A) and (B). The heat maps indicate the intensity of phosphorylation on the following specific sites: ErbB3 (pY1325) and p85 (pY467). The lane corresponding to tumour 1186 has been removed due to sample degradation. Because phosphorylation of Y1325 was not detected in HER2 tumour 3051 by MS, the positive signal obtained by Western blotting may reflect cross-reactivity of the commercial antibody with a different phosphorylation site on erbB3 or another erbB receptor.

Additional file 8: Figure S6. Unsupervised hierarchical clustering using the $707 \mathrm{pY}$ sites identified in p53 tumours. (Imputation: $k-N N+$ column mean).

Additional file 9: Table S3. Proteins showing $>10$-fold increased phosphorylation in 1203/4 versus the other p53 tumours.

Additional file 10: Table S4. Amplified regions on chromosome 6 for the eight p53 tumours.

Additional file 11: Table S5. Pathway analysis of proteins showing $>10$-fold increased phosphorylation in 1203/4 versus other p53 tumours.

Additional file 12: Figure S7. (A) MET knockdown using siRNA in cell lines derived from p53-null mouse tumours. Western blots were incubated with the indicated antibodies. \# in 1201 indicates nonspecific band. (B) Effect of MET knockdown on cell proliferation by MTS assay measuring relative absorbance. At least three independent sets of replicate experiments were performed with the same trend observed. Data from one representative experiment are shown. ${ }^{*} P<0.05$ and ${ }^{*} P<0.005$ by $t$-test (siRNA treated vs control). 'Control' refers to ON-TARGETplus nontargeting siRNA, and 'Pool' refers to SMARTpool consisting of four individual siRNAs targeting mouse MET.

\section{Abbreviations}

aCGH: Array comparative genomic hybridisation; ANOVA: Analysis of variance; EMT: Epithelial-mesenchymal transition; FDR: False discovery rate; GEM: Genetically engineered mouse; Gprc5c: G protein-coupled receptor family C, group 5, member C; IP: Immunoprecipitation; $k$-NN: $k$-nearest neighbour; MMTV: Mouse mammary tumour virus; MS/MS: Tandem mass spectrometry; nano-LC-MS/MS: Nano-liquid chromatography tandem mass spectrometry; PI3K: Phosphatidylinositol 3-kinase; PINA: Protein interaction network analysis; pY: Phosphotyrosine; PyMT: Polyoma virus middle T antigen; RTK: Receptor tyrosine kinase; SFK: Src family kinase.

\section{Competing interests}

The authors declare that they have no competing interests.

\section{Authors' contributions}

RJD conceived and designed the study. NAA, FH, HC, RN, SY, LZ and RJL undertook the experiments. JW, MP, HCL and NA performed bioinformatics analysis on the generated data sets. AS, CJO and SJC assisted with experimental design and data interpretation. NAA, AS and RJD wrote the paper. All authors read and approved the paper before submission.

\section{Acknowledgments}

This work was supported by the National Health and Medical Research Council of Australia, the National Breast Cancer Foundation and the Cancer Council New South Wales. AS is a Career Development Fellow of the National Health and Medical Research Council of Australia.

\section{Author details}

${ }^{1}$ Cancer Research Program, The Kinghorn Cancer Centre, Garvan Institute of Medical Research, 370 Victoria Street, Sydney, NSW 2010, Australia. ${ }^{2}$ Current Address: Junior Research Group Pathoproteomics, Competence Center in Functional Genomics, University of Greifswald, F.-L.-Jahnstr. 15, Greifswald 17489, Germany. ${ }^{3}$ Current Address: Department of Biochemistry and Molecular Biology, School of Biomedical Sciences, Monash University, Level 1, Building 77, Clayton, VIC 3800, Australia. ${ }^{4}$ School of Mathematics and Statistics, The University of Sydney, Room 637, Carslaw Building F07, Sydney, NSW 2006, Australia.

Received: 2 December 2013 Accepted: 1 September 2014 Published online: 09 September 2014

\section{References}

1. Yarden $Y$, Pines $G$ : The ERBB network: at last, cancer therapy meets systems biology. Nat Rev Cancer 2012, 12:553-563.

2. Kalinsky K, Jacks LM, Heguy A, Patil S, Drobnjak M, Bhanot UK, Hedvat CV, Traina TA, Solit D, Gerald W, Moynahan ME: PIK3CA mutation associates with improved outcome in breast cancer. Clin Cancer Res 2009, 15:5049-5059.

3. Creedon $\mathrm{H}$, Brunton VG: Src kinase inhibitors: promising cancer therapeutics? Crit Rev Oncog 2012, 17:145-159.

4. Celebi JT, Adams SJ, Aydin IT: GAB2-a scaffolding protein in cancer. Mol Cancer Res 2012, 10:1265-1270

5. Banerji S, Cibulskis K, Rangel-Escareno C, Brown KK, Carter SL, Frederick AM, Lawrence MS, Sivachenko AY, Sougnez C, Zou L, Cortes ML, FernandezLopez JC, Peng S, Ardlie KG, Auclair D, Bautista-Piña V, Duke F, Francis J, Jung J, Maffuz-Aziz A, Onofrio RC, Parkin M, Pho NH, Quintanar-Jurado V, Ramos AH, Rebollar-Vega R, Rodriguez-Cuevas S, Romero-Cordoba SL, Schumacher SE, Stransky N, et al: Sequence analysis of mutations and translocations across breast cancer subtypes. Nature 2012, 486:405-409.

6. Bentires-Alj M, Gil SG, Chan R, Wang ZC, Wang Y, Imanaka N, Harris LN, Richardson A, Neel BG, Gu H: A role for the scaffolding adapter GAB2 in breast cancer. Nat Med 2006, 12:114-121.

7. Brough R, Frankum JR, Sims D, Mackay A, Mendes-Pereira AM, Bajrami I, Costa-Cabral S, Rafiq R, Ahmad AS, Cerone MA, Natrajan R, Sharpe R, Shiu KK, Wetterskog D, Dedes K, Lambros MB, Rawjee T, Linardopoulos S, Reis-Filho JS, Turner NC, Lord CJ, Ashworth A: Functional viability profiles of breast cancer. Cancer Discov 2011, 1:260-273.

8. Ursini-Siegel J, Schade B, Cardiff RD, Muller WJ: Insights from transgenic mouse models of ERBB2-induced breast cancer. Nat Rev Cancer 2007, 7:389-397.

9. Yuan W, Stawiski E, Janakiraman V, Chan E, Durinck S, Edgar KA, Kljavin NM, Rivers CS, Gnad F, Roose-Girma M, Haverty PM, Fedorowicz G, Heldens S, 
Soriano RH, Zhang Z, Wallin JJ, Johnson L, Merchant M, Modrusan Z, Stern HM, Seshagiri S: Conditional activation of $P i k 3 \mathrm{ca}^{\mathrm{H} 1047 \mathrm{R}}$ in a knock-in mouse model promotes mammary tumorigenesis and emergence of mutations. Oncogene 2012, 32:318-326.

10. Hudis CA: Trastuzumab-mechanism of action and use in clinical practice. N Engl J Med 2007, 357:39-51.

11. Brenton JD, Carey LA, Ahmed AA, Caldas C: Molecular classification and molecular forecasting of breast cancer: ready for clinical application? J Clin Oncol 2005, 23:7350-7360.

12. Rakha EA, Reis-Filho JS, Ellis IO: Basal-like breast cancer: a critical review. J Clin Oncol 2008, 26:2568-2581.

13. Graveel CR, DeGroot JD, Su Y, Koeman J, Dykema K, Leung S, Snider J, Davies SR, Swiatek PJ, Cottingham S, Watson MA, Ellis MJ, Sigler RE, Furge KA, Vande Woude GF: Met induces diverse mammary carcinomas in mice and is associated with human basal breast cancer. Proc Natl Acad Sci U S A 2009, 106:12909-12914.

14. Nielsen TO, Hsu FD, Jensen $K$, Cheang M, Karaca G, Hu Z, HernandezBoussard T, Livasy C, Cowan D, Dressler L, Akslen LA, Ragaz J, Gown AM, Gilks CB, van de Rijn M, Perou CM: Immunohistochemical and clinical characterization of the basal-like subtype of invasive breast carcinoma. Clin Cancer Res 2004, 10:5367-5374.

15. Ponzo MG, Lesurf R, Petkiewicz S, O'Malley FP, Pinnaduwage $D$, Andrulis IL, Bull SB, Chughtai N, Zuo D, Souleimanova M, Germain D, Omeroglu A, Cardiff RD, Hallett M, Park M: Met induces mammary tumors with diverse histologies and is associated with poor outcome and human basal breast cancer. Proc Natl Acad Sci U S A 2009, 106:12903-12908.

16. Hochgräfe F, Zhang L, OToole SA, Browne BC, Pinese M, Porta Cubas A, Lehrbach GM, Croucher DR, Rickwood D, Boulghourjian A, Shearer R, Nair R, Swarbrick A, Faratian D, Mullen P, Harrison DJ, Biankin AV, Sutherland RL, Raftery MJ, Daly RJ: Tyrosine phosphorylation profiling reveals the signaling network characteristics of basal breast cancer cells. Cancer Res 2010, 70:9391-9401.

17. Grigoriadis A, Mackay A, Noel E, Wu PJ, Natrajan R, Frankum J, Reis-Filho JS, Tutt A: Molecular characterisation of cell line models for triple-negative breast cancers. BMC Genomics 2012, 13:619.

18. Vargo-Gogola T, Rosen JM: Modelling breast cancer: one size does not fit all. Nat Rev Cancer 2007, 7:659-672.

19. Fluck MM, Schaffhausen BS: Lessons in signaling and tumorigenesis from polyomavirus middle T antigen. Microbiol Mol Biol Rev 2009, 73:542-563.

20. Webster MA, Hutchinson JN, Rauh MJ, Muthuswamy SK, Anton M, Tortorice CG, Cardiff RD, Graham FL, Hassell JA, Muller WJ: Requirement for both Shc and phosphatidylinositol 3 ' kinase signaling pathways in polyomavirus middle T-mediated mammary tumorigenesis. Mol Cell Biol 1998, 18:2344-2359

21. Herschkowitz JI, Simin K, Weigman VJ, Mikaelian I, Usary J, Hu Z, Rasmussen KE, Jones LP, Assefnia S, Chandrasekharan S, Backlund MG, Yin Y, Khramtsov Al, Bastein R, Quackenbush J, Glazer RI, Brown PH, Green JE, Kopelovich L, Furth PA, Palazzo JP, Olopade OI, Bernard PS, Churchill GA, Van Dyke T, Perou CM: Identification of conserved gene expression features between murine mammary carcinoma models and human breast tumors. Genome Biol 2007, 8:R76.

22. Herschkowitz Jl, Zhao W, Zhang M, Usary J, Murrow G, Edwards D, Knezevic J, Greene SB, Darr D, Troester MA, Hilsenbeck SG, Medina D, Perou CM, Rosen JM: Comparative oncogenomics identifies breast tumors enriched in functional tumor-initiating cells. Proc Natl Acad Sci U S A 2012, 109:2778-2783.

23. Jerry DJ, Kittrell FS, Kuperwasser C, Laucirica R, Dickinson ES, Bonilla PJ Butel JS, Medina D: A mammary-specific model demonstrates the role of the $p 53$ tumor suppressor gene in tumor development. Oncogene 2000, 19:1052-1058

24. Bennett CN, Green JE: Unlocking the power of cross-species genomic analyses: identification of evolutionarily conserved breast cancer networks and validation of preclinical models. Breast Cancer Res 2008, 10:213.

25. Bennett CN, Green JE: Genomic analyses as a guide to target identification and preclinical testing of mouse models of breast cancer. Toxicol Pathol 2010, 38:88-95.

26. Nair R, Roden DL, Teo WS, McFarland A, Junankar S, Ye S, Nguyen A, Yang J, Nikolic I, Hui M, Morey A, Shah J, Pfefferle AD, Usary J, Selinger C, Baker LA, Armstrong N, Cowley MJ, Naylor MJ, Ormandy CJ, Lakhani SR, Herschkowitz Jl, Perou CM, Kaplan W, O'Toole SA, Swarbrick A: c-Myc and Her2 cooperate to drive a stem-like phenotype with poor prognosis in breast cancer. Oncogene 2013, 33:3992-4002.

27. Bargmann $\mathrm{Cl}$, Weinberg RA: Increased tyrosine kinase activity associated with the protein encoded by the activated neu oncogene. Proc Natl Acad Sci U S A 1988, 85:5394-5398.

28. Van Pariis L, Refaeli Y, Lord JD, Nelson BH, Abbas AK, Baltimore D: Uncoupling IL-2 signals that regulate T cell proliferation, survival, and Fas-mediated activation-induced cell death. Immunity 1999, 11:281-288.

29. Swarbrick A, Roy E, Allen T, Bishop JM: Id1 cooperates with oncogenic Ras to induce metastatic mammary carcinoma by subversion of the cellular senescence response. Proc Natl Acad Sci U S A 2008, 105:5402-5407.

30. Welm AL, Kim S, Welm BE, Bishop JM: MET and MYC cooperate in mammary tumorigenesis. Proc Natl Acad Sci U S A 2005, 102:4324-4329.

31. Zhang M, Behbod F, Atkinson RL, Landis MD, Kittrell F, Edwards D, Medina D, Tsimelzon A, Hilsenbeck S, Green JE, Michalowska AM, Rosen JM: Identification of tumor-initiating cells in a p53-null mouse model of breast cancer. Cancer Res 2008, 68:4674-4682.

32. Guy CT, Cardiff RD, Muller WJ: Induction of mammary tumors by expression of polyomavirus middle T oncogene: a transgenic mouse model for metastatic disease. Mol Cell Biol 1992, 12:954-961.

33. Cox J, Neuhauser N, Michalski A, Scheltema RA, Olsen JV, Mann M: Andromeda: a peptide search engine integrated into the MaxQuant environment. J Proteome Res 2011, 10:1794-1805.

34. Troyanskaya O, Cantor M, Sherlock G, Brown P, Hastie T, Tibshirani R, Botstein D, Altman RB: Missing value estimation methods for DNA microarrays. Bioinformatics 2001, 17:520-525.

35. Strimmer K: A unified approach to false discovery rate estimation. BMC Bioinformatics 2008, 9:303.

36. Breiman L: Random forests. Mach Learn 2001, 45:5-32.

37. Cowley MJ, Pinese M, Kassahn KS, Waddell N, Pearson JV, Grimmond SM, Biankin AV, Hautaniemi S, Wu J: PINA v2.0: mining interactome modules. Nucleic Acids Res 2012, 40:D862-D865.

38. Wu J, Vallenius T, Ovaska K, Westermarck J, Mäkelä TP, Hautaniemi S: Integrated network analysis platform for protein-protein interactions. Nat Methods 2009, 6:75-77.

39. Hornbeck PV, Kornhauser JM, Tkachev S, Zhang B, Skrzypek E, Murray B, Latham V, Sullivan M: PhosphoSitePlus: a comprehensive resource for investigating the structure and function of experimentally determined post-translational modifications in man and mouse. Nucleic Acids Res 2012, 40:D261-D270.

40. Shi G, Zhang L, Jiang T: MSOAR 2.0: incorporating tandem duplications into ortholog assignment based on genome rearrangement. BMC Bioinformatics 2010, 11:10.

41. Wu J, Mao X, Cai T, Luo J, Wei L: KOBAS server: a web-based platform for automated annotation and pathway identification. Nucleic Acids Res 2006, 34:W720-W724.

42. Xie C, Mao X, Huang J, Ding Y, Wu J, Dong S, Kong L, Gao G, Li CY, Wei L: KOBAS 2.0: a web server for annotation and identification of enriched pathways and diseases. Nucleic Acids Res 2011, 39:W316-W322.

43. Benjamini $Y$, Hochberg $Y$ : Controlling the false discovery rate: a practical and powerful approach to multiple testing. I R Stat Soc Series B Methodol 1995, 57:289-300.

44. Janes PW, Daly RJ, deFazio A, Sutherland RL: Activation of the Ras signalling pathway in human breast cancer cells overexpressing erbB-2. Oncogene 1994, 9:3601-3608.

45. Olshen $A B$, Venkatraman ES, Lucito R, Wigler M: Circular binary segmentation for the analysis of array-based DNA copy number data. Biostatistics 2004, 5:557-572.

46. Bioconductor Open Source Software for Bioinformatics: DNAcopy: DNA copy number data analysis. [http://www.bioconductor.org/packages/ release/bioc/html/DNAcopy.html] (accessed 15 September 2014).

47. R Project for Statistical Computing: R-2.15.2. [http://cran.r-project.org/bin/ windows/base/old/2.15.2/] (accessed 15 September 2014).

48. Brummer T, Schramek D, Hayes VM, Bennett HL, Caldon CE, Musgrove EA, Daly RJ: Increased proliferation and altered growth factor dependence of human mammary epithelial cells overexpressing the Gab2 docking protein. J Biol Chem 2006, 281:626-637.

49. PhosphoSitePlus. [http://www.phosphosite.org/] (accessed 15 September 2014).

50. Guy CT, Muthuswamy SK, Cardiff RD, Soriano P, Muller WJ: Activation of the c-Src tyrosine kinase is required for the induction of mammary tumors in transgenic mice. Genes Dev 1994, 8:23-32. 
51. Hellman A, Zlotorynski E, Scherer SW, Cheung J, Vincent JB, Smith DI, Trakhtenbrot L, Kerem B: A role for common fragile site induction in amplification of human oncogenes. Cancer Cell 2002, 1:89-97.

52. Xu K, Usary J, Kousis PC, Prat A, Wang DY, Adams JR, Wang W, Loch AJ, Deng T, Zhao W, Cardiff RD, Yoon K, Gaiano N, Ling V, Beyene J, Zacksenhaus E, Gridley T, Leong WL, Guidos CJ, Perou CM, Egan SE: Lunatic fringe deficiency cooperates with the Met/Caveolin gene amplicon to induce basal-like breast cancer. Cancer Cell 2012, 21:626-641.

53. Smolen GA, Muir B, Mohapatra G, Barmettler A, Kim WJ, Rivera MN Haserlat SM, Okimoto RA, Kwak E, Dahiya S, Garber JE, Bell DW, Sgroi DC, Chin L, Deng CX, Haber DA: Frequent met oncogene amplification in a Brca1/Trp53 mouse model of mammary tumorigenesis. Cancer Res 2006 , 66:3452-3455.

54. Abella JV, Peschard P, Naujokas MA, Lin T, Saucier C, Urbé S, Park M: Met/hepatocyte growth factor receptor ubiquitination suppresses transformation and is required for Hrs phosphorylation. Mol Cell Biol 2005, 25:9632-9645.

55. Croucher DR, Hochgräfe F, Zhang L, Liu L, Lyons RJ, Rickwood D, Tactacan CM, Browne BC, Ali N, Chan H, Shearer R, Gallego-Ortega D, Saunders DN, Swarbrick A, Daly RJ: Involvement of Lyn and the atypical kinase SgK269/PEAK1 in a basal breast cancer signaling pathway. Cancer Res 2013, 73:1969-1980.

56. Rikova K, Guo A, Zeng Q, Possemato A, Yu J, Haack H, Nardone J, Lee K, Reeves C, Li Y, Hu Y, Tan Z, Stokes M, Sullivan L, Mitchell J, Wetzel R, MacNeill J, Ren JM, Yuan J, Bakalarski CE, Villen J, Kornhauser JM, Smith B, Li D, Zhou X, Gygi SP, Gu TL, Polakiewicz RD, Rush J, Comb MJ: Global survey of phosphotyrosine signaling identifies oncogenic kinases in lung cancer. Cell 2007, 131:1190-1203.

57. Hodgson JG, Malek T, Bornstein S, Hariono S, Ginzinger DG, Muller WJ, Gray JW: Copy number aberrations in mouse breast tumors reveal loci and genes important in tumorigenic receptor tyrosine kinase signaling. Cancer Res 2005, 65:9695-9704.

58. Sáez R, Molina MA, Ramsey EE, Rojo F, Keenan EJ, Albanell J, Lluch A, García-Conde J, Baselga J, Clinton GM: p95HER-2 predicts worse outcome in patients with HER-2-positive breast cancer. Clin Cancer Res 2006 12:424-431.

59. Pedersen K, Angelini PD, Laos S, Bach-Faig A, Cunningham MP, Ferrer-Ramón C, Luque-García A, García-Castillo J, Parra-Palau JL, Scaltriti M, Ramón y Cajal S, Baselga J, Arribas J: A naturally occurring HER2 carboxy-terminal fragment promotes mammary tumor growth and metastasis. Mol Cell Biol 2009, 29:3319-3331.

60. Zhang X, Pickin KA, Bose R, Jura N, Cole PA, Kuriyan J: Inhibition of the EGF receptor by binding of MIG6 to an activating kinase domain interface. Nature 2007, 450:741-744.

61. Nagashima T, Ushikoshi-Nakayama R, Suenaga A, Ide K, Yumoto N, Naruo Y, Takahashi K, Saeki Y, Taiji M, Tanaka H, Tsai SF, Hatakeyama M: Mutation of epidermal growth factor receptor is associated with MIG6 expression. FEBS J 2009, 276:5239-5251.

62. Wang Z, Raines LL, Hooy RM, Roberson H, Leahy DJ, Cole PA: Tyrosine phosphorylation of Mig6 reduces its inhibition of the epidermal growth factor receptor. ACS Chem Biol 2013, 8:2372-2376.

63. Jechlinger M, Sommer A, Moriggl R, Seither P, Kraut N, Capodiecci P, Donovan M, Cordon-Cardo C, Beug H, Grünert S: Autocrine PDGFR signaling promotes mammary cancer metastasis. J Clin Invest 2006, 116:1561-1570.

64. Lemmon MA, Schlessinger J: Cell signaling by receptor tyrosine kinases. Cell 2010, 141:1117-1134.

65. Cuevas BD, Lu Y, Mao M, Zhang J, LaPushin R, Siminovitch K, Mills GB: Tyrosine phosphorylation of $\mathrm{p} 85$ relieves its inhibitory activity on phosphatidylinositol 3-kinase. J Biol Chem 2001, 276:27455-27461.

66. Cook RS, Garrett JT, Sánchez V, Stanford JC, Young C, Chakrabarty A, Rinehart C, Zhang Y, Wu Y, Greenberger L, Horak ID, Arteaga CL: ErbB3 ablation impairs PI3K/Akt-dependent mammary tumorigenesis. Cancer Res 2011, 71:3941-3951.

67. Shah SP, Roth A, Goya R, Oloumi A, Ha G, Zhao Y, Turashvili G, Ding J, Tse K, Haffari G, Bashashati A, Prentice LM, Khattra J, Burleigh A, Yap D, Bernard V, McPherson A, Shumansky K, Crisan A, Giuliany R, Heravi-Moussavi A, Rosner J, Lai D, Birol I, Varhol R, Tam A, Dhalla N, Zeng T, Ma K, Chan SK, et al: The clonal and mutational evolution spectrum of primary triple-negative breast cancers. Nature 2012, 486:395-399.
68. Network CGA: Comprehensive molecular portraits of human breast tumours. Nature 2012, 490:61-70.

69. Knight JF, Lesurf R, Zhao H, Pinnaduwage D, Davis RR, Saleh SM, Zuo D, Naujokas MA, Chughtai N, Herschkowitz J, Prat A, Mulligan AM, Muller WJ, Cardiff RD, Gregg JP, Andrulis IL, Hallett MT, Park M: Met synergizes with p53 loss to induce mammary tumors that possess features of claudin-low breast cancer. Proc Natl Acad Sci U S A 2013, 110:E1301-E1310

70. Hitosugi T, Kang S, Vander Heiden MG, Chung TW, Elf S, Lythgoe K, Dong S, Lonial S, Wang X, Chen GZ, Xie J, Gu TL, Polakiewicz RD, Roesel JL, Boggon TJ, Khuri FR, Gilliland DG, Cantley LC, Kaufman J, Chen J: Tyrosine phosphorylation inhibits PKM2 to promote the Warburg effect and tumor growth. Sci Signal 2009, 2:ra73.

71. Hitosugi T, Zhou L, Fan J, Elf S, Zhang L, Xie J, Wang Y, Gu TL, Alečković M, LeRoy G, Kang Y, Kang HB, Seo JH, Shan C, Jin P, Gong W, Lonial S, Arellano ML, Khoury HJ, Chen GZ, Shin DM, Khuri FR, Boggon TJ, Kang S, He C, Chen J: Tyr26 phosphorylation of PGAM1 provides a metabolic advantage to tumours by stabilizing the active conformation. Nat Commun 2013, 4:1790

72. Berger MF, Hodis E, Heffernan TP, Deribe YL, Lawrence MS, Protopopov A, Ivanova E, Watson IR, Nickerson E, Ghosh P, Zhang H, Zeid R, Ren X, Cibulskis K, Sivachenko AY, Wagle N, Sucker A, Sougnez C, Onofrio R Ambrogio L, Auclair D, Fennell T, Carter SL, Drier Y, Stojanov P, Singer MA, Voet D, Jing R, Saksena G, Barretina J, et al: Melanoma genome sequencing reveals frequent PREX2 mutations. Nature 2012, 485:502-506.

doi:10.1186/s13058-014-0437-3

Cite this article as: Ali et al:: Profiling the tyrosine phosphoproteome of different mouse mammary tumour models reveals distinct, modelspecific signalling networks and conserved oncogenic pathways. Breast Cancer Research 2014 16:437.

\section{Submit your next manuscript to BioMed Central and take full advantage of:}

- Convenient online submission

- Thorough peer review

- No space constraints or color figure charges

- Immediate publication on acceptance

- Inclusion in PubMed, CAS, Scopus and Google Scholar

- Research which is freely available for redistribution 